\title{
Biological and physical drivers of bio-mediated sediment resuspension: A flume study on Cerastoderma edule
}

\author{
Cozzoli Francesco 1, 2, 3, ${ }^{*}$, Gomes Da Conceição Tatiana ${ }^{2}$, Van Dalen Jeroen ${ }^{2}$, Fang Xiaoyu ${ }^{4}$, \\ Gjoni Vojsava ${ }^{1}$, Herman Peter M.J. ${ }^{5,6}$, Hu Zhan ${ }^{7,8,}{ }^{*}$, Soissons Laura ${ }^{2,9}$, Walles Brenda ${ }^{10}$, \\ Ysebaert Tom ${ }^{2,10}$, Bouma Tjeerd J.
}

1 Dipartimento di Scienze e Tecnologie Biologiche ed Ambientali, University of the Salento, 73100, Lecce, Italy

2 Department of Estuarine and Delta Systems. Royal Netherlands Institute of Sea Research (NIOZ) and Utrecht University, 4401, NT Yerseke, the Netherlands

${ }^{3}$ Research Institute on Terrestrial Ecosystems (IRET) - National Research Council of Italy (CNR), via

Salaria km 29.3 - 00015, Monterotondo Scalo (Roma), Italy

${ }^{4}$ Marine Biology Research Group, Department of Biology, Ghent University, 9000, Ghent, Belgium

${ }^{5}$ Department of Hydraulic Engineering, Delft University of Technology, 2628 CN, P.O. Box 5048

2600GA, Delft, the Netherlands

${ }^{6}$ Deltares, P.O. Box 177 2600, MH, Delft, the Netherlands

7 Guangdong Provincial Key Laboratory of Marine Resources and Coastal Engineering and School of

Marine Science, Sun Yat-sen University, Guangzhou, China

${ }^{8}$ Southern Marine Science and Engineering Guangdong Laboratory, Zhuhai, China

${ }^{9}$ MARBEC, Univ. Montpellier, CNRS, Ifremer, IRD, Sète, France

10 Wageningen Marine Research, Wageningen University and Research, P.B. 77, 4400 AB, Yerseke, the Netherlands

* Corresponding authors : Francesco Cozzoli, email address : francesco.cozzoli@unisalento.it ; Zhan Hu, email address : huzh9@mail.sysu.edu.cn

\begin{abstract}
:
Predictive models accounting for the effect of bioturbation on sediment resuspension must be based on ecological theory as well as on empirical parametrizations. The scaling trend of individual metabolic and activity rates with body mass may be a key to the mechanistic understanding of the observed patterns. With this study we tested if general size scaling rules in bio-mediated sediment resuspension may apply to a broad range of physical contexts for the endobenthic bivalve Cerastoderma edule. The effect on sediment resuspension of populations of $\mathrm{C}$. edule differing by individual size was measured across physical gradients of current velocity and sediment composition in terms of fraction of fine particles. C. edule were able to enhance the resuspension of sediment containing silt, while they had scarce effect on the resuspension of coarse sediment. The effect of bioturbation was maximal at intermediate current velocity, when the hydrodynamic forcing is not strong enough to overcome the abiotic sediment resistance but it is able to suspend the bioturbated sediment. Although differences in sediment silt content and intensities of hydrodynamic stress have a relevant influence in determining the bioturbators individual contribution to sediment resuspension, the observed mass scaling trend is consistent across all treatments and close to theoretical expectation for size scaling of individual metabolic rates. This observation supports the hypothesis that the contribution of individual bioturbators to sediment
\end{abstract}


resuspension is directly related to their energy use. Therefore, the proposed approach allows the formulation of expectations of biotic contribution to sediment resuspension based on the general size scaling laws of individual energy use.

\section{Highlights}

- Bioturbators affect sediment resuspension. The effect of bioturbators was compared across different sediment types. Bioturbation effect was maximal at intermediate current and on cohesive sediment. The individual effect of bioturbators scales with size similarly to metabolic rate. The size scaling trend is independent of the sediment composition.

Keywords : Bioturbation, Cohesiveness, Body size, Allometry, Sediment resuspension, Cerastoderma edule 


\section{Introduction}

Sediment resuspension is mainly driven by the interaction between hydrodynamic forcing and sediment particles (Le Hir, et al., 2000; Winterwerp \& van Kesteren, 2004; Fagherazzi \& Wiberg, 2009; Zhou, et al., 2015), the outcome of which may be heavily modulated by biotic agents (Le Hir, et al., 2007; Grabowski, et al., 2011; Friedrichs, 2011; Wilkes, et al., 2019). In particular, the macrozoobenthic organisms disrupt and remix the sediment with their moving, feeding and respiration activities in a process called bioturbation (Meysman, et al., 2006; Kristensen, et al., 2012). Bioturbation alters the bottom sediment composition, geochemistry and erodibility (Le Hir, et al., 2007; Sandford, 2008; Gogina, et al., 2018; Li, et al., 2019). It happens at a local scale, but the effects may be important for broader landscape processes (Widdows \& Brinsley, 2002; Bentley Sr, et al., 2014; Walles, et al., 2015). The bioturbators' ecosystem engineering [sensu (Jones, et al., 1994; Jones, et al., 1997)] of wet sediment dynamics impacts the short- and long-term development of coastal geomorphology (Winterwerp, et al., 2018; Gao, 2019), ecology (Zhu, et al., 2016; Lukwambe, et al., 2018; Mermillod-Blondin, et al., 2018; Savelli, et al., 2019) and services provided to the human society (Barbier, 2013; Bouma, et al., 2014; Lin, et al., 2018; Silva, et al., 2019). The role of bioturbation should hence be taken into account in order to implement Ecosystem-Based management of coastal areas (Braeckman, et al., 2014; Van der Biest, et al., 2020).

The large majority of flume experiments [e.g. (Widdows, et al., 1998; Willows, et al., 1998; Orvain, et al., 2003; Kristensen, et al., 2013; Rakotomalala, et al., 2015; Cozzoli, et al., 2019)], field observations [e.g. (Neumeier, et al., 2006; Montserrat, et al., 2008; Harris, et al., 2015; Joensuu, et al., 2018; Hillman, et al., 2019)] and simulation studies [e.g. (Sandford, 2008; Orvain, et al., 2012; Nasermoaddeli, et al., 2018; Angeletti, et al., 2019)] agree that the presence of bioturbators generally enhance sediment resuspension. However, bio-mediated sediment dynamics often have complex non-linear behaviour (Balke, et al., 2012; Salvador 
de Paiva, et al., 2018; Fang, et al., 2019; Xie, et al., 2019). For instance, some field transplantation studies report tidal flat accretion in presence of high densities of the bioturbator Cerastoderma edule (Andersen, et al., 2010; Donadi, et al., 2013), whereas flume studies often show an increase in sediment resuspension.

Predictive models of bio-mediated physical dynamics should be based on generally valid physicochemical and biological laws (van Prooijen, et al., 2011), able to encompass the broad span of functional (Queirós, et al., 2013) and spatial (Gogina, et al., 2020) diversity observed in nature. The individual size is a generally valid descriptor of the intensity of individual bioturbation activity, with larger bioturbators having a higher bioturbation potential (Solan, et al., 2004b; Gilbert, et al., 2007) and generating a greater increase in resuspension of bottom sediment (Cozzoli, et al., 2018; Cozzoli, et al., 2019) and chlorophyll-a (Rakotomalala, et al., 2015). This is because individual metabolic and activity rates increase with the individual body mass following a power law with a scaling exponent of 0.66 or 0.75 (West, et al., 1997; Kooijman, 2000; Vladimirova, et al., 2003; van der Meer, 2006; Hou, et al., 2008; Brey, 2010). A scaling exponent positive but lower than unity implies that, although the overall individual metabolic rate increase with body mass, the metabolic rate per unit of mass decrease with body mass with a scaling exponent of -0.33 or -0.25 . The mass scaling of metabolic rates is considered one of the most "universal" trends in ecology and it has implications at any level of organization. Models based on the mass scaling of metabolic rates can be used to predict general trends from individuals to ecosystems (Brown, et al., 2004; Harris, et al., 2006; Martin, et al., 2013). In the case of bioturbation, the allometric scaling of metabolic rates implies that larger individuals, having stronger respiration, feeding, burrowing and moving activity, generate larger mechanical disturbance and hence weaken a larger volume of the surrounding sediment. However, smaller individuals should have a larger effect per unit of body mass because of their higher mass specific metabolic rate. Metabolic scaling 
of bioturbation potential highlights the importance of the size structure of bioturbator communities in determining the bioturbator influence on sediment characteristics (Cozzoli, et al., 2018; Wrede, et al., 2019). The relationship between bioturbators metabolic rates at population level and bio-mediated effects on sediment resuspension are generally valid for a range of hydrodynamics stress conditions and a range of taxonomic and functional diversity of the bioturbators (Cozzoli, et al., 2019).

Not only the intrinsic characteristics of the bioturbators, but also the extrinsic environmental context can generate variations in bio-mediated sediment resuspension. In particular, the sediment composition in terms of particle size distribution strongly affects resistance to erosion. Silty (particles diameters $<63 \mu \mathrm{m}$ ) and sandy (particles diameters between $63 \mu \mathrm{m}$ and $2 \mathrm{~mm}$ ) sediments have different physical - chemical properties: as opposed to sand, silt particles develop an asymmetric electrical charge distribution on their surfaces. This exerts a net attractive force between particles, called cohesion. Once the amount of fine particles reaches a certain threshold ( $c a .10 \%)$, cohesion forces confer plasticity and "stickiness" to the whole sediment mass, making it less erodible (van Ledden, et al., 2004; Winterwerp \& van Kesteren, 2004). Erosion and resuspension of non-cohesive sediment occurs once the hydrodynamic stress exceeds the threshold for particle motion. The drivers of cohesive sediment resuspension are more complex and relate not only to particle size and hydrodynamic stress but also to the sediment compaction and mineral composition (Hayter \& Mehta, 1986; Winterwerp \& van Kesteren, 2004; van Prooijen \& Winterwerp, 2010) and to the presence of microphytobenthos, which glues together sediment grains by producing extracellular polymeric substance and hence increases sediment resistance to erosion (Sutherland \& Grant, 1998). The resuspension of sediments with different levels of cohesiveness may be differently influenced by the effect of bioturbation activity. For instance, recent field observations (Harris, et al., 2015; Joensuu, et al., 2018; Bernard, et al., 2019; 
Hillman, et al., 2019), flume studies (Li, et al., 2017; Soissons, et al., 2019) and sediment transport models (Nasermoaddeli, et al., 2018) showed that bioturbators enhance the resuspension of fine sediment but have limited influence on coarse sediment.

Physical and biological drivers of sediment resuspension may establish complex interactions, the effect of which has not yet been fully understood. In particular, the relationship between bioturbators individual mass and bio-mediated sediment resuspension has not yet been investigated across a range of extrinsic environmental conditions such as the composition and degree of cohesiveness of the bioturbated sediment. Whereas field observations can be used to investigate the effect of benthic organisms on sediment resuspension [e.g. (Orvain, et al., 2007; Andersen, et al., 2010; Ubertini, et al., 2012; Savelli, et al., 2019)], stochasticity and covariance between explanatory variables in the natural environment hamper the mechanistic understanding of the processes involved. Studies conducted over fully factorial experimental designs (i.e. crossing all combinations of target sources of variation) under controlled (mesocosm) conditions are needed to disentangle the role of the different intrinsic and extrinsic drivers of bio-mediated sediment dynamics (Orvain, et al., 2006; van Prooijen, et al., 2011). Therefore, we used recirculating annular flumes in controlled mesocosm conditions to test the hypotheses that the effect of the bioturbators on sediment resuspension should reflect the intrinsic scaling trends of individual metabolic and activity rates over a range of extrinsic conditions in terms of hydrodynamic stress and sediment silt fraction. 


\section{Material and Methods}

\subsection{Experimental design}

The principal idea of this experiment is to explore how sediment resuspension is influenced by physical and biological drivers (Figure 1). Therefore, we used a mesocosm approach to quantify the importance of these drivers under controlled conditions, excluding bioturbator behavioural changes in response to other environmental cues [e.g. acidification (YvonDurocher, et al., 2012; Ong, et al., 2017); temperature (Verdelhos, et al., 2015a); salinity (Verdelhos, et al., 2015b); food availability (Maire, et al., 2006)]. By mixing different types of natural sediments, we were able to obtain 4 different levels of sediment silt volume content $(0 \%, 4 \%, 10 \%$ and $28 \%$, Table 1$)$ ranging from sand to sandy mud (van Rijn, 2007). Recirculating annular flumes were used to simulate the natural dynamic changes in current velocity during the tidal flooding of a mudflat (from 5 to $30 \mathrm{~cm} \mathrm{sec}^{-1}$ by steps of $5 \mathrm{~cm} \mathrm{sec}^{-1}$, each step lasting 20 minutes). Variations in sediment resuspension were approximated from water turbidity. To better focus on the contribution of the individual bioturbation activity, we kept the overall bioturbators biomass constant (19 $\mathrm{g}$ Ash Free Dry Weight $\mathrm{m}^{-2}$ ) as we simultaneously varied the body size and the density of the tested specimens. Four different size classes of individuals were used (36, 93, 247 and $576 \mathrm{mg}$ AFDW of individual body mass, Table 2). We chose to use an intermediate overall biomass of $C$. edule to avoid overlapping between individuals' areas of influence (Zwarts, et al., 1994; Willows, et al., 1998; van Prooijen, et al., 2011; Cozzoli, et al., 2018) while still having a clear and detectable effect on sediment resuspension. Following a factorial design, each experimental treatment (2 replicates) was representative of a unique combination of bioturbators' individual size and sediment composition in terms of silt content, for a total of 32 experimental runs with bioturbators, each of which always used homogeneously sized individuals. Each of the experimental runs with bioturbators was associated to a control run using the same sediment 
type and current velocity gradient but without bioturbators. Considering that 6 repeated measurements were taken at different current velocity levels for each run, we collected a total of 384 data points (192 observations from bioturbated runs +192 observations from control runs, Figure 1). A numbers of replicates per treatment higher than the 2 we used would have possibly given greater reliability ad reproducibility to our analysis. However, the logistic efforts necessary for empirical testing did not make it possible to collect other measures. While the dataset we collected may be regarded as not being "optimal", it is one of the most complete experimental datasets (to our knowledge) on biota-mediated sediment resuspension that has been measured according to gradients of individual size, individuals' density, hydrodynamic energy and sediment composition. The obtained dataset is available as appendix of this study (Appendix A) and in the OSF repository at DOI

\subsection{5/OSF.IO/BCWFH.}

\subsection{Model organisms}

In this experiment, we used as model organism the bivalve Cerastoderma edule (Linnaeus, 1758). C. edule (common cockle) is a species of saltwater clam in the family of Cardiidae which is widely distributed in waters off northern Europe as far north as Iceland and into waters of western Africa as far south as Senegal (Boyden, 1971). The ribbed oval shells can reach $6 \mathrm{~cm}$ across and are white, yellowish or brown in colour. C. edule is a key element of estuarine food webs, consuming suspended organic matter and being a main source of food for birds (Bijleveld, et al., 2016). It is harvested commercially and eaten in much of its range (Boyden, 1971). According to the Oosterschelde (NL) observations presented in (Cozzoli, et al., 2014), this species can reach a relatively large individual body mass (up to $600 \mathrm{mg}$ Ash Free Dry Weight; on average $177 \mathrm{mg}$ AFDW \pm 202 s.d.), high density (up to 457 Ind. $\mathrm{m}^{-2}$; on average 94 Ind. $\mathrm{m}^{-2} \pm 55$ s.d.) and biomass (up to $84 \mathrm{~g} \mathrm{AFDW} \mathrm{m}^{-2}$; on average $16 \mathrm{~g}$ AFDW $\mathrm{m}^{-2} \pm 20$ s.d.). C. edule is commonly found in a large variety of sediments ranging from fine 
mud to sand, with a preference for cohesive sediments (Cozzoli, et al., 2013). The thermal optimum for $C$. edule activity is $20-23{ }^{\circ} \mathrm{C}$, above which the activity of the animal decreases due to thermal stress, until a $100 \%$ of mortality when exposed for 120 hours to $32{ }^{\circ} \mathrm{C}$ (Verdelhos, et al., 2015a). The salinity optimum is around 20-25, with a tolerance range from fully marine (35) to brackish (10-15) (Verdelhos, et al., 2015b). Ocean acidification, especially if associated to warming, may have a detrimental effect on physiological performances and fitness of C. edule (Ong, et al., 2017).

C. edule is a filter feeder and shallow endobenthic burrower. Its short siphons usually emerge from the sediment surface (Flach, 1996). Field and laboratory observations showed that its reworking of the sediment is mostly related to bio-deposition, vertical and horizontal movements and valve adduction that destabilize the cohesive sediment, making it more erodible [e.g. (Flach, 1996; Ciutat, et al., 2007; Montserrat, et al., 2009; Li, et al., 2017)]. By doing so, bioturbation by $C$. edule also enhances the resuspension of organic material and microphytobenthos (Ubertini, et al., 2012; Rakotomalala, et al., 2015). The feeding rate of $C$. edule is not significantly affected by changes in current speed, at least between 5 and $35 \mathrm{~cm}$ $\sec ^{-1}$ (Widdows \& Navarro, 2007). The material filtered out from the water column is deposited in the form of faeces (digested organic material) and pseudofaeces (discarded sediment). Loose mucus bound pseudofaeces have a lower erosion threshold (current velocity of $\left.15 \mathrm{~cm} \mathrm{sec}^{-1}\right)$ compared to faecal pellets $\left(25 \mathrm{~cm} \mathrm{sec}^{-1}\right)$. At flows below these thresholds, biodeposits generated from $C$. edule tend to sediment and accumulate on the bed (Widdows \& Navarro, 2007).

C. edule is an excellent model organism to study bioturbation effects with high potential for generalization because: $i$ ) it adapts well to laboratory conditions; $i$ ) it constitutes a predominant portion of the bioturbators intertidal biomass (Kater, et al., 2006) on a broad geographical scale (Boyden, 1971); iii) recent evidence showed that the effect of this species 
on sediment resuspension is common to a broad range of bioturbators functional types (Cozzoli, et al., 2018; Cozzoli, et al., 2019); iv) the physiology and energetic of $C$. edule has been carefully investigated due to the relevance of this species as ecological indicator and bioaccumulator of pollutants (Fernández-Tajes, et al., 2011) v) its commercial importance for shell fisheries and clam digging (Boyden, 1971).

\subsection{Experimental devices}

The recirculating annular flumes we used are a variation of the design described by (Widdows, et al., 1998). The annular channel has a surface of $157 \mathrm{~cm}^{2}$ and an overall height of $40 \mathrm{~cm}$, of which the bottom $5 \mathrm{~cm}$ are filled with a pebbled bed to allow water drainage, followed by $10 \mathrm{~cm}$ of consolidated sediment and $20 \mathrm{~cm}$ of filtered marine seawater $(31.4 \mathrm{~L})$. The water motion is generated by a smooth disk rotating $3 \mathrm{~cm}$ below the water surface, which is driven by a microprocessor-controlled engine. Technical drawings and pictures of the annular flume can be found in Appendix B. An acoustic Doppler velocimetry probe was used to calibrate water velocity as a function of engine rotation speed. Water turbidity is measured using an optical backscatter sensor (OBS 3+, Campbell scientific) facing the water perpendicularly to the current direction at a height of $10 \mathrm{~cm}$ from the sediment surface. The effect of suspended sediment on light absorption was measured by the OBS sensors in nephelometric turbidity units every 30 seconds and converted into suspended sediment concentration $\left(\mathrm{g} \mathrm{L}^{-1}\right)$ based on calibration by gravitometric analysis (Appendix B).

\subsection{Experimental procedures}

Sediment preparation: The sediment was collected in late winter 2015 at location Oesterdam

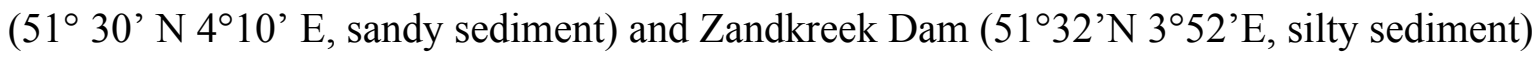
in the Oosterschelde and carefully sieved over a $1 \mathrm{~mm}$ sieve to avoid the presence of large particles (stones, shells, wooden pieces) and remove larger animals. Successively, the 
sediment was covered with a thick black plastic film for at least two weeks and sieved again to remove remaining residual fauna. For each type of sediment composition, a homogeneous matrix was obtained by adding silty sediment to a sandy matrix until reaching the desired level of silt. The sediment was mixed manually. During mixing and sequential silt addition, the percentage of silt in the sediment mass was measured by using a Malvern Mastersizer $2000 ®$ particle size analyser. Following this procedure, we obtained 4 different types of sediment compositions, with no (0\%), low (4\%), intermediate (10\%) and high (28\%) silt volume fraction (Table 1). The so prepared wet sediment was put in the flumes, mixed to a smooth mass and allowed to consolidate until creating a layer of $10 \mathrm{~cm}$ height with a smooth surface. Excess water in the sediment was drained through the pebbled bed placed at the bottom. After $96 \mathrm{~h}$, the flumes were filled with $31.4 \mathrm{~L}$ of filtered seawater (height of the water column $20 \mathrm{~cm}$ ). To prevent damage to the freshly-consolidated sediment surface, a sheet of bubble plastic was placed on top of it before gently spraying water into the flume. Although the sediment bottoms we obtained by this procedure may slightly differ from the natural ones in term of grain size distribution, compaction and porewater gradient (Porter, et al., 2006), they offer a representation of the sediment cohesiveness gradient that may be observed along a mudflat tidal transect (Cozzoli, et al., 2013).

\section{Collection and measurement of specimens: $C$. edule specimens were collected at the} Oesterdam during spring 2015. The authorization for specimen collection was issued by the competent authority Rijkswaterstaat. After collection, the specimens were allowed to acclimate for two weeks in a mesocosm at $18{ }^{\circ} \mathrm{C}$. During the acclimation period, the specimens were kept in the same sediment used for the experiment. Four different shell length classes $(15,20,27$ and $35 \mathrm{~mm}$ of shell diameter $[ \pm 0.5 \mathrm{~mm}$ measurement error $])$ were selected to cover the $C$. edule size gradient commonly observed in nature (Table 2). Individual sizes were expressed as individual body masses ( $M$, mg Ash Free Dry Weight) and 
were estimated from the length of the cockles' shells according to the length-mass relationships provided from the Monitor Taskforce of the Royal Netherlands Institute for Sea Research (NIOZ), Yerseke. The mortality during the experiment was low and the specimens were released at the collection site at the end of the experiments.

Specimens addition: A total biomass of $3 \mathrm{~g}$ AFDW (corresponding to $19 \mathrm{~g} \mathrm{AFDW} \mathrm{m}^{-2}$ ) of $C$. edule specimens of four different size classes (Table 2) were evenly distributed over the sediment surface and allowed to settle for $48 \mathrm{~h}$. The choice of a longer time interval ( $48 \mathrm{~h})$ compared with the typical interval between erosion stress peaks (typically 12 or $24 \mathrm{~h}$ in a tidal system) was necessary to give the animals the time to properly settle in the new environment and recover from manipulation stress. Most of them were buried within a few minutes after being placed in the flume and non-burrowing individuals were replaced. During their presence in the flume, some specimens crawled on and below the sediment surface, leaving evident tracks.

Erosion runs: To simulate the natural dynamic changes in current velocity during flood tide, we increased the current velocity $\left(V, \mathrm{~cm} \mathrm{sec}^{-1}\right)$ from 5 to $30 \mathrm{~cm} \mathrm{sec}^{-1}$ in steps of $5 \mathrm{~cm} \mathrm{sec}^{-1}$, each step lasting 20 minutes. According to (Roberts, et al., 2000) and using a constant friction factor for the sediment surface of 0.002 , the range of current velocity used should correspond to a range of bottom shear stresses between 0.05 and $0.25 \mathrm{~Pa}$ for a flat bottom. Biogenic bottom roughness may increase the friction factor in presence of bioturbators, implying a damping of bottom shear stress (Friedrichs, 2011; Anta, et al., 2013).

Bioturbator and control treatments have been prepared and run simultaneously. Each treatment ( 2 bioturbated runs +2 control runs) was carried out on the same day. According to the availability of experimental flumes and considering the long preparation time to obtain a consolidated bottom, we took $c a .2$ months to complete the experiment.

\subsection{Data Analysis}


In this study, we did not consider extremely high values of suspended sediment deriving by general failures of the flume bed and consequent mass erosion (Mehta \& Partheniades, 1982; van Prooijen \& Winterwerp, 2010), although such mass erosion happened in some treatments. Therefore, the collected dataset was preliminary inspected and records of mass erosion events were removed from the analysis. We also removed some records clearly biased by optical disturbance to the OBS sensor.

To express sediment resuspension in spatial units, we converted the measured suspended sediment concentration $\left(S S C, \mathrm{~g} \mathrm{~L}^{-1}\right)$ to total mass of suspended sediment per unit of sediment surface $\left(R_{T O T}, \mathrm{~g} \mathrm{~m}^{-2}\right)$ as:

$$
R_{\text {TOT }}=\frac{\text { SSC*Volume }}{\text { Area }} \quad \text { Eq. } 1
$$

where Area is the surface area of the experimental flumes $\left(0.157 \mathrm{~m}^{2}\right)$ and Volume is the amount of contained water $(31.4 \mathrm{~L})$. The development of sediment erosion at the increase of current velocity in the experimental flumes was analysed by visual inspection of the erosion curves. Following (Kristensen, et al., 2013), the erosion thresholds, expressed as critical flow velocity for starting sediment resuspension $\left(V, \mathrm{~cm} \mathrm{sec}^{-1}\right)$ were estimated for each treatment as the zero $R_{\text {TOT }}$ intercept from a regression of $R_{T O T}$ measured at the end of each velocity step (i.e. average $R_{T O T}$ recorded during of the last two minutes of each current velocity step) against $V$. Only measurements above the erosion threshold were used for this calculation. The amount of suspended sediment due to bioturbation $R_{B I O}\left(\mathrm{~g} \mathrm{~m}^{-2}\right)$ was calculated for each replicate as:

$$
R_{\text {BIO }}=R_{\text {TOT }}^{\text {(Bioturbated })}-R_{\text {TOT }} \text { (Control) } \quad \text { Eq. } 2
$$




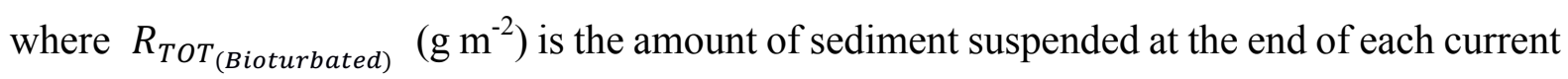
velocity step in the bioturbated treatment and $R_{\text {TOT }}$ (Control) $\left(\mathrm{g} \mathrm{m}^{-2}\right)$ is the amount of sediment suspended in the corresponding control treatment.

The variation in $R_{B I O}$ across experimental treatments and increasing current velocity $(V, \mathrm{~cm}$ $\mathrm{sec}^{-1}$ ) steps was analysed by linear mixed ANCOVA. The different types of sediment composition in terms of silt fraction (Silt) were used as categorical explanatory variable. The current velocity $\left(V, \mathrm{~cm} \mathrm{sec}^{-1}\right)$ and the individual mass of the bioturbators $(M, \mathrm{mg}$ AFDW) were used as continuous explanatory variables. The response variable $R_{B I O}$ and the explanatory variable $M$ were normalized via log transformation. A third degree polynomial function of the explanatory variable $V$ was used to account for asymmetric concavity in the shape of relationship between current velocity and $R_{B I O}$ :

$$
\log \left(R_{B I O}\right) \sim \log (M) *\left(V+V^{2}+V^{3}\right) * \text { Silt } \quad \text { Eq. } 3
$$

where the operator "*" indicates use of the individual variables and their interaction terms. We included the experimental runs as random term in the ANCOVA to account for nonindependence of the observations. This allows to treat properly the effect of $V$, which is affected by repeated measurements during each erosion run. Selection of predictive variables and interaction terms was assessed by bi-directional stepwise elimination procedure. All analyses were performed within the free software environment R ( $\mathrm{R}$ Core Team, 2019) using the package lme4 (Bates, et al., 2015) and lmerTest (Kuznetsova, et al., 2017). 


\section{Results}

\subsection{Erosion curves}

General bottom failure and mass erosion occurred at some current velocities $\left(V, \mathrm{~cm} \mathrm{sec}^{-1}\right)$ (all the bioturbated treatments above $V$ of $20 \mathrm{~cm} \mathrm{sec}^{-1}$ for the sediment with $4 \%$ silt content), for some replicates (one replicate each for the treatments with $10 \%$ and $28 \%$ silt content and individual body mass $M$ of $36 \mathrm{mg}$ AFDW) and for one entire treatment (silt content $10 \%$ and $M=247 \mathrm{mg}$ AFDW). These observations were probably related to lack of consolidation of the sediment in the experimental flumes and outranged the turbidity sensor detection range. Therefore, they were not considered in the following analyses (Figure 2).

In the absence of bioturbation, the critical flow velocity for erosion varied from $13.6 \mathrm{~cm} \mathrm{sec}^{-1}$ for sediment with $28 \%$ of silt to $17.2 \mathrm{~cm} \mathrm{sec}^{-1}$ for sediment with $8 \%$ of silt (Figure 2, Table 3). Sediments with $0 \%$ and $4 \%$ of silt content were the most erodible at the higher current velocity ( $>20 \mathrm{~cm} \mathrm{sec}^{-1}$ ), reaching a $R_{T O T}$ value of $121 \pm 27.18$ (s. d.) $\mathrm{g} \mathrm{m}^{-2}$ and $187 \pm 115 \mathrm{~g}$ $\mathrm{m}^{-2}$ at maximal $V\left(30 \mathrm{~cm} \mathrm{sec}^{-1}\right)$, respectively (Figure 2$)$. As we realized during the experiment, $R_{\text {TOT }}$ values for the sediment with $0 \%$ silt content may be slightly overestimated due to the presence of some unidentified kind of organic matter generating a small amount of foam and light hampering at high current velocity. Although we washed the sediment several times, we were not able to remove this effect. Mass erosion was observed in some not bioturbated controls for the sediment with $4 \%$ of silt content at $V$ of $30 \mathrm{~cm} \mathrm{sec}^{-1}$. Sediments with $10 \%$ and $28 \%$ of silt content had relatively low values of $R_{T O T}\left(61 \pm 59 \mathrm{~g} \mathrm{~m}^{-2}\right.$ and $36 \pm$ $74 \mathrm{~g} \mathrm{~m}^{-2}$, respectively) even at water velocity of $30 \mathrm{~cm} \mathrm{sec}^{-1}$ (Figure 2).

For bioturbated treatments with $0 \%$ of silt content, we observed a moderate increase in $R_{T O T}$ at intermediate $V$ values only $\left(15-25 \mathrm{~cm} \mathrm{sec}^{-1}\right)$ for $M=36 \mathrm{mg}$ AFDW and $M=247 \mathrm{mg}$ AFDW. In these two treatments we also observed a decrease in critical flow velocity for erosion from 15.5 to $8.5 \mathrm{~cm} \mathrm{sec}^{-1}$. A moderate decrease in $R_{T O T}$ at maximal $V$ was observed in 
the two other bioturbated treatments $(M=93 \mathrm{mg}$ AFDW and $\mathrm{M}=576 \mathrm{mg}$ AFDW) (Figure 2). The presence of $C$. edule had the strongest effect on $R_{T O T}$ in the treatments with $4 \%$ of silt content. In this case, the bioturbators generated a decrease in the critical flow velocity for erosion from 15.2 to $c a .5 \mathrm{~cm} \mathrm{sec}^{-1}\left(9 \mathrm{~cm} \mathrm{sec}^{-1}\right.$ in the treatment with $\mathrm{M}=576 \mathrm{mg}$ AFDW, Table 3). This led to a moderate increase of $R_{T O T}$ already at $V=10 \mathrm{~cm} \mathrm{sec}^{-1}$ (especially the two smaller size classes) and a very strong increase at $V$ between 10 and $20 \mathrm{~cm} \mathrm{sec}^{-1}$. The presence of bioturbators triggered mass erosion at $V=25 \mathrm{~cm} \mathrm{sec}^{-1}$ (Figure 2). C. edule had also a strong effect on sediment resuspension at $10 \%$ and $28 \%$ of silt content, although without trigging mass erosion. In the case of the bioturbated sediment with $10 \%$ of silt content, the critical flow velocity for erosion decreased from 17.2 to $10-12 \mathrm{~cm} \mathrm{sec}^{-1}$ (Table 3 ). A consistent increase in $R_{T O T}$ due to bioturbation activity was observed starting from $V=15$ $\mathrm{cm} \mathrm{sec}^{-1}$ and continuously increasing with $V$ until a value of $+150 \pm 16 \mathrm{~g} \mathrm{~m}^{-2}$ for the treatment with $M=93 \mathrm{mg}$ AFDW. Bioturbators did not affect the critical flow velocity for erosion of the sediment with $28 \%$ of silt content (ca. $12 \mathrm{~cm} \mathrm{sec}^{-1}$, Table 3 ). Above this threshold the bioturbators enhanced the erosion flux, leading to a maximal increment in $R_{T O T}$ of $+153 \pm 19 \mathrm{~g} \mathrm{~m}^{-2}$ for the treatment with $M=36 \mathrm{mg}$ AFDW (Figure 2).

\subsection{Biotic contribution to sediment resuspension}

Following the logarithmic transformation, the negative values of mass of suspended sediment due to bioturbation activity $\left(R_{B I O}, \mathrm{~g} \mathrm{~m}^{-2}\right.$, Equation 2$)$ were excluded from the analysis. Negative values of $R_{B I O}$ implies a decrease in sediment resuspension in presence of bioturbators and were observed mostly in the sediment with $0 \%$ silt content. As a consequence of this selection and of that one made previously to avoid observations biased by optical disturbance to the sensor, the total number of $R_{B I O}$ values included in the analysis has dropped to 135 (Table 4). The full mixed ANCOVA model of the variation $R_{B I O}$ using the silt content of the sediment (Silt), the current velocity $\left(V, \mathrm{~cm} \mathrm{sec}^{-1}\right)$ and the individual mass of 
the bioturbators ( $M$, mg AFDW) as explanatory variables (Equation 3) was simplified by bidirectional elimination stepwise procedure. Following this procedure, the square term of the polynomial of $V$, the third order interaction terms and some of the second order interaction terms were eliminated. The full model (i.e. prior to variables selection) is available as an appendix (Appendix C). The fixed terms in the simplified ANCOVA model explains $76 \%$ of the observed variance in $R_{B I O}$, while random variation among experimental runs was able to explain the $8 \%$ only (Table 5).

The model has good performances in predicting $R_{B I O}$ for sediment with silt content higher than $0 \%$. Given the low influence of the bioturbators on the resuspension of the pure sandy sediment (Figure 2), the model fails in predicting $R_{B I O}$ for these treatments (Figure 3, Figure 4). $R_{B I O}$ significantly $(p<0.001)$ increases with the increase of $V$ independently from the sediment silt content and the body mass of bioturbators (Table 5, Figure 3, Figure 4). The significant $(p<0.001)$ and negative coefficient for $V^{3}$ implies a concave shape in the relationship between $R_{B I O}$ and $V$ (Table 5, Figure 3 ). The concavity of the relationship varies significantly $(p<0.001)$ across sediment silt contents, being maximal for the sandy sediment, intermediate for sediments with $10 \%$ and $28 \%$ silt content and minimal for the sediment with $4 \%$ of silt content (Table 5, Figure 3 ). However, the nearly linear relationship between $V$ and $R_{B I O}$ estimated for the sediment with $4 \%$ silt content is likely to be an experimental artefact related to the lack of observations for bioturbated treatments at $V$ higher than $20 \mathrm{~cm} \mathrm{sec}^{-1}$ (Figure 2). Independently of the intensity of $V$ and with only marginal variation across types of sediment composition $(p>0.05), R_{B I O}$ scales significantly $(p<0.001)$ and negatively (scaling exponent $=-0.42 \pm 0.22)$ with $M$ (Table 5, Figure 4). 


\section{Discussion}

In our experiments we used a full factorial combination of physical (sediment composition, hydrodynamic stress) and biological (bioturbator size/density ratio) drivers of bio-mediated sediment resuspension to disentangle the specific importance of each component and reveal the effect of their interactions (Figure 1). Although sediment resuspension patterns change across sediment types, the intrinsic scaling to the individual mass of the bioturbators was independent of the extrinsic physical context.

\subsection{Effect of hydrodynamic stress and sediment composition on bio-mediated sediment resuspension}

In accordance with previous flumes (Li, et al., 2017; Soissons, et al., 2019) and field (Harris, et al., 2015; Joensuu, et al., 2018; Bernard, et al., 2019) observations, bioturbation had a limited influence on the resuspension of pure sandy sediment, whereas it had a strong influence on resuspension of silt-containing sediments, even if only a low amount of silt was present ( $4 \%$ volume fraction). In the case of sandy sediment, increments in sediment resuspension can be related to the exposure of otherwise buried fine particles to the buoyant action of the water (Volkenborn, et al., 2009; van Prooijen, et al., 2011). In the case of cohesive sediment, the bioturbation disrupts the cohesiveness and compaction in the upper sediment layers, generating a fluff layer (Shimeta, et al., 2002; Orvain, et al., 2003; Orvain, 2005). The fluff layer is less resistant to erosion than the not-bioturbated sediment, so that bioturbation decreases the critical flow velocity for erosion and enhances the erosion fluxes of cohesive sediment. Therefore, $C$. edule changed the sediment response to hydrodynamic stress by making the otherwise erosion-resistant cohesive sediments as erodible as the noncohesive ones. Above the threshold for cohesiveness (10\% silt fraction), the effects of bioturbation on sediment resuspension no longer increases with sediment silt content. These observations support what was recently predicted by a landscape-scale model of biota- 
mediated sediment resuspension on the basis of field observations of suspended sediment concentration: the resuspension of fine silt in the southern North Sea is very sensitive to the occurrence of bioturbators, whereas coarser sediment particles are less affected (Nasermoaddeli, et al., 2018).

Our results suggest that if the hydrodynamic forcing is limited, the contribution of bioturbation on sediment resuspension is relatively low. As well, if the hydrodynamics are strong enough (or the sediment resistance weak enough, as it is in the case of non-cohesive sediment) to erode the non-bioturbated sediment, the relative contribution of bioturbators to sediment resuspension decreases because the additional bioturbation is less relevant for particle motion. Bioturbation effects are maximal at intermediate current velocity, when the hydrodynamic forcing is not strong enough to overcome the abiotic sediment resistance (that is enhanced by cohesiveness) but are able to suspend the bioturbated sediment. This interpretation is in line with the observations of (Moore, 2006), who noted that ecosystem engineering in river morphodynamics can be more important with moderate hydrodynamic energy and high bioturbators activity. Tending to be zero at very high and very low current velocities for each type of sediment, the amount of suspended sediment due to bioturbation activity has per se only marginally significant changes across sediment types. Neither is changing its linear relationship with the current velocity. What actually changes across the types of sediment is the current velocity at which bioturbators peak their effect on resuspension. In sandy sediments, the bioturbators have a maximal effect at current velocity of $20 \mathrm{~cm} \mathrm{sec}^{-1}$, above which the hydrodynamic stress starts to be able to suspend the nonbioturbated sediment. Assuming a concave shape for the relationship between current velocity and bioturbators contribution to sediment resuspension (Equation 3, Table 5), the maximal effect on cohesive sediment resuspension should occur at a current velocity of $c a .40 \mathrm{~cm} \mathrm{sec}^{-1}$. It also follows that the current velocity at which the bioturbators no longer have an 
appreciable effect on the resuspension $\left(i . e<1 \mathrm{~g} \mathrm{~m}^{-2}\right.$ ) of the sediment is greater for the cohesive sediment $\left(c a .60 \mathrm{~cm} \mathrm{sec}^{-1}\right)$ than for the non-cohesive $\left(c a .40 \mathrm{~cm} \mathrm{sec}^{-1}\right)$. It must be however considered that our observations concern supply-limited erosion only (Mehta \& Partheniades, 1982; van Prooijen \& Winterwerp, 2010). At current velocity higher than the maximal we tested or in presence of waves, mass erosion (that may be triggered or anticipated by the presence of bioturbators, as we observed in the treatments with $4 \%$ of silt content) may deviate from our expectations.

\subsection{Allometric scaling of individual contribution to sediment resuspension}

Given a fixed biomass, the contribution of a population of bioturbators to sediment resuspension decrease with the bioturbators individual size. The estimated mass scaling exponent $(-0.42 \pm 0.22)$ is different from either 0 (i.e. bio-mediated sediment resuspension directly proportional to the population biomass) and -1 (i.e. bio-mediated sediment resuspension directly proportional to the individuals' density in the case of biomass equivalence across size classes). It is instead close to the theoretical expectations of -0.33 or 0.25 for size scaling of individual metabolic rates per unit of biomass. In this respect, our observations support the hypothesis that the contribution of bioturbators to sediment resuspension is related to their metabolic and activity rate, rather than to their mere presence, biovolume or spatial density (Cozzoli, et al., 2018; Cozzoli, et al., 2019). Therefore, a certain biomass of smaller organism would generate a stronger disturbance of the sediment than the same biomass of larger organisms because smaller organisms have higher metabolic rates per unit of body mass. It follows that information on the size structure of the bioturbating communities [e.g. (Gjoni, et al., 2017; Gjoni \& Basset, 2018)] and on the individual metabolic responses to internal and external conditions [e.g. (Rosenfeld, et al., 2015; Shokri, et al., 2019)] is needed to predict the bioturbation effects on sediment resuspension. Extrapolations based on bioturbators' overall biomass or density should instead be treated 
with caution, because they may estimate wrongly the contribution of individuals differing by body mass and activity level.

Although differences in sediment silt content and intensities of hydrodynamic stress have a relevant influence in determining the bioturbators' individual contribution to sediment resuspension, the observed mass scaling trend is constant across all treatments. Therefore, size allometries in bio-mediated sediment resuspension can be generally applied to different sediment compositions as well as to different functional types of bioturbators (Cozzoli, et al., 2018; Cozzoli, et al., 2019). This finding expands the possibility to simplify and generalize the process-based modelling of bioturbators-sediment interactions [sensu (van Prooijen, et al., 2011)] by establishing a link between the energetic of the organisms and their effect on the surrounding environment (Humphries \& McCann, 2014). As an example referred to field conditions, the bioturbators size, overall biomass and community bioturbation activity generally peak in the intermediate-high part of the mudflat, where the hydrodynamic energy is moderate and the sediment has an intermediate to high silt fraction (Pearson \& Rosenberg, 1978; Nilsson \& Rosenberg, 2002), i.e. where bioturbators are also more effective in enhancing sediment resuspension. Thus, our results confirm and strengthen the hypothesis that bioturbators mostly enhance the erosion of the upper shore, potentially inducing a downward shift of the tidal flat (Wood \& Widdows, 2002; Orvain, et al., 2012). More generally, distribution models of benthic populations in relation to hydrodynamic and sediment characteristics can be used to produce spatially explicit estimates of the individual mass, abundance and therefore the potential effect on sediment resuspension of bioturbators in natural conditions.

\subsection{Mechanisms to be further investigated}

In this study we attribute the changes in turbidity to changes in sediment erodibility. 
However, some other mechanisms involved in bio-mediated sediment resuspension must be considered. C. edule filter particles that are suspended in the water column while feeding. The clearance activity may affect the amount of turbidity measured in the water in recirculating flumes, possibly leading to an underestimation of the effect of $C$. edule bioturbation on erosion rate, compared to field settings. This underestimation can reach a factor of 2 in the case of chlorophyll-a suspension (Rakotomalala, et al., 2015). Despite deserving to be examined more carefully, three main arguments suggests that suspended sediment filtration can generate only a minor bias on our observations. Firstly, the filtered sediment is not retained in the body of the bioturbators, but it is rather quickly expelled in the form of pseudofaeces, that are easily erodible and likable to be re-suspended immediately at current velocity $>15 \mathrm{~cm} \mathrm{sec}^{-1}$ (Widdows \& Navarro, 2007), i.e. with a similar critical flow velocity for erosion to cohesive not-bioturbated sediment. Still, part of the decrease in suspended sediment at high current velocity that we observed in some treatments with noncohesive sediment could be related to increased sediment strength by pelletization (Briggs, et al., 2015). Secondly, being both fuelled by the individual metabolic rate, the magnitude of the physiological activities involved in sediment destabilization and of the individual clearance rate increase with body mass (decrease per unit of mass) with a similar scaling exponent (Smaal, et al., 1997), leading to a substantial process balance across size classes. Thirdly, previous studies comparing multiple types of bioturbators in a similar experimental setup (Cozzoli, et al., 2018; Cozzoli, et al., 2019) did not show relevant differences in the resuspension of sediment in the presence of filter feeders (e.g. C. edule) or bottom-feeders (e.g. Arenicola marina).

Another mechanism to be further investigated is the effect of the structural modification of the bottom surface roughness by bioturbators, which can be generated both in autologous (emerging shells) and allogenic (disruption of the sediment surface) way. Bio-mediated 
increases in bottom roughness could shelter the sediment surface from shear flow (Friedrichs, et al., 2009; Friedrichs, 2011; Anta, et al., 2013). In the case of cohesive sediment, increased bottom roughness may generate a reduction in sediment resuspension when the hydrodynamic forcing is low (shear stress $<10 \mathrm{~cm} \mathrm{sec}^{-1}$ ) and/or the bioturbators abundance (Ciutat, et al., 2007) or activity (Cozzoli, et al., 2019) is higher than what used in this experiment. The reduction in cohesive sediment resuspension is suppressed at higher hydrodynamic stress by the opposite destabilizing effect (Cozzoli, et al., 2019). With the current experiment we show that, in case on pure sandy sediment, the sheltering and pelletization effects could be the predominant influence of bioturbators, leading to a minor reduction in sand resuspension at high current stress $\left(30 \mathrm{~cm} \mathrm{sec}^{-1}\right)$, even at the relatively low number of organisms we used.

It must also be considered that in our experiment the individual body mass was calculated based on shell length. Given the approximately spherical shape of $C$. edule, the individual mass scales with the shell length with an exponent close to 3 (actually, 2.8). Therefore, our observation could be eventually interpreted as an inverse proportionality between shell length and effect on sediment resuspension $\left(2.8^{*}-0.42=-1.12\right)$, which further leads to other influencing factors such as burial depth, destabilization sediments beyond the surface layer and autogenous modification of the bottom roughness. This interpretation should be rejected considering that: $i$ ) given the experimental design we used, an inverse proportionality to the individual length should exclude any effect of the individuals numerical density or total biomass, and this is contrasting with all previous knowledge $i$ ) previous experiments comparing bioturbators with different physical shapes and therefore different scaling coefficient for the mass $\sim$ length relationship and/or generating different morphological alterations of the bottom surface and/or with different burying depth related to their body length showed no significant change in bioturbation effect on sediment resuspension 
(Cozzoli, et al., 2018; Cozzoli, et al., 2019).

Finally, factorial experiments accounting for the effect of temperature change on biomediated sediment resuspension could offer a definitive confirmation of the dependence on metabolism of bioturbator populations. Water temperature is indeed a key regulator of metabolic rates in ectotherms such as macrozoobenthic bioturbators (Brown, et al., 2007). Beyond the effect of variation in physical factors (Nguyen, et al., 2019) it is expected that the biotic contribution to sediment resuspension should increase positively with temperature similarly to the individual metabolic rates, i.e. according to a positive Boltzmann - Arrhenius relationship (Brown, et al., 2007). Therefore, metabolic-based approaches may help explaining global and seasonal variations in biotic influences on sediment dynamics (Cozzoli, et al., 2018; Wrede, et al., 2018). 


\section{Conclusion}

With this study, we quantified the role of major sources of abiotic and biotic variability in enhancing sediment resuspension by highlighting the combined role of physical and biological factors in determining sediment resuspension. We observed that differences in sediment silt content and intensities of hydrodynamic stress have a major influence in determining the final amount of suspended sediment. However, the observed mass scaling trend of bioturbators' individual contribution to sediment resuspension is $i$ ) close to the size scaling trend of individual metabolic rates and $i$ ) constant at the variation of the environmental conditions. In the light of these findings, the bioturbators can be seen as energy transfer units that convert the chemical energy contained in the food web into kinetic energy that is discharged onto the sediment. The observation of a mass scaling exponent similar to that of mass specific individual metabolic rates suggests that a somehow constant fraction of metabolic energy is discharged onto the sediment at individual level. While the intensity of the energy flow is determined by the body size and energy requirement of the bioturbators, its effect on sediment resuspension is mediated by the hydrodynamic stress and the mechanical characteristics of the sediment itself.

The metabolic dependency of bio-mediated sediment dynamics that we describe places our observations within the broader context of metabolic ecological theories [e.g. (Kooijman, 2000; Brown, et al., 2004; Glazier, 2005; Hou, et al., 2008)]. It establishes a connection between ecosystem engineering and general models of organisms metabolic [e.g. (YvonDurocher, et al., 2012)] and demographic [e.g. (Dossena, et al., 2012; Lindmark, et al., 2018; Bryndum-Buchholz, et al., 2019; Jørgensen, et al., 2019)] responses to global environmental changes. Hence, our observations supports the parametrization of general, predictive models of bio-mediated sediment dynamics at local [e.g . (Aquino, et al., 2017; Winterwerp, et al., 2018)], tidal transect [e.g. (Wood \& Widdows, 2002; Orvain, et al., 2012)] and landscape [e.g. 
(Nasermoaddeli, et al., 2018; Angeletti, et al., 2019)] scale. By doing so, they open a venue to the formulation of general expectations about future scenarios of bio-mediated sediment resuspension. 
We gratefully thank the following people and companies: Conrad Pilditch for providing insights on the flumes realization; Jansen Tholen B.V. for realisation of the flumes, Lowie Haazen, Bert Sinke, Jos van Soelen for their indispensable technical support and for their patience, Francis Orvain for the insightful comments that greatly improved the quality of the manuscript. This work was supported by the Building with Nature program, which received funding from the Dutch Ministry of Transport, Public Works and Water Management, the municipality of Dordrecht, EFRO as well as the participants to the Foundation EcoShape, with contribution from the CoE-Oesterdam project and the Guangdong Provincial Department of Science and Technology (2019ZT08G090). At the time of starting this project, NIOZ-Yerseke belonged to the Netherlands Institute of Ecology. 


\section{References}

Andersen, T. J. et al., 2010. Erodibility of a mixed mudflat dominated by microphytobenthos and Cerastoderma edule, East Frisian Wadden Sea, Germany. Estuar. Coast. Mar. Sci., Volume 87, pp. 197-206.

Angeletti, S., Pierini, J. O. \& Cervellini, P. M., 2019. Suspended sediment contribution resulting from bioturbation in intertidal sites of a SW Atlantic mesotidal estuary: data analysis and numerical modelling. Sci. Mar., 82(4), pp. 245-256.

Anta, J., Peña, E., Puertas, J. \& Cea, L., 2013. A bedload transport equation for the Cerastoderma edule cockle. J. Mar. Sys., Volume 111, pp. 189-195.

Aquino, T. et al., 2017. A process-based model for bioturbation-induced mixing. Sci. Rep., 7(1), p. 14287.

Balke, T. et al., 2012. Conditional outcome of ecosystem engineering: A case study on tussocks of the salt marsh pioneer Spartina anglica. Geomorphology, Volume 153, pp. 232-238.

Barbier, E., 2013. Valuing ecosystem services for coastal wetland protection and restoration: Progress and challenges. Resources, 2(3), pp. 213-230.

Bates, D., Maechler, M., Bolker, S. \& Walker, S., 2015. Fitting linear mixed-effects models using lme4. J. Stat. Soft., Volume 67, pp. 1-48.

Bentley Sr, S. J., Swales, A., Pyenson, B. \& Dawe, J., 2014. Sedimentation, bioturbation, and sedimentary fabric evolution on a modern mesotidal mudflat: A multi-tracer study of processes, rates, and scales. Estuar. Coast. Mar. Sci., Volume 141, pp. 58-68.

Bernard, G. et al., 2019. Quantifying bioturbation across coastal seascapes: Habitat characteristics modify effects of macrofaunal communities. J. Sea Res., Volume 152, p. 101766. 
Bijleveld, A. I. et al., 2016. Understanding spatial distributions: negative density-dependence in prey causes predators to trade-off prey quantity with quality. Proc. R. Soc. B, Volume 283, p. 20151557.

Bouma, T. J. et al., 2014. Identifying knowledge gaps hampering application of intertidal habitats in coastal protection: Opportunities \& steps to take. Coast. Eng., Volume 87, pp. 147-157.

Boyden, C. R., 1971. A note on the nomenclature of two European cockles. Zool. J. Linnean Soc., Volume 50, pp. 307-310.

Braeckman, U. et al., 2014. Protecting the commons: the use of subtidal ecosystem engineers in marine management. Aquatic Conserv: Mar. Freshw. Ecosyst., Volume $10.1002 /$ aqc. 2448 .

Brey, T., 2010. An empirical model for estimating aquatic invertebrate respiration. Methods Ecol. Evol., Volume 1, p. 92-101.

Briggs, K., Cartwright, G., Friedrichs, C. \& Shivarudruppa, S., 2015. Biogenic effects on cohesive sediment erodibility resulting from recurring seasonal hypoxia on the Louisiana shelf. Cont. Shelf Res., Volume 93, pp. 17-26.

Brown, J., Allen, A. \& Gillooly, J., 2007. The metabolic theory of ecology and the role of body size in marine and freshwater ecosystems. In: Body size: the structure and function of aquatic ecosystems. Cambrige: Cambridge University Press, pp. 1-15.

Brown, J. et al., 2004. Toward a metabolic theory of Ecology. Ecology, Volume 82, p. 17711789.

Bryndum-Buchholz, A. et al., 2019. Twenty-first-century climate change impacts on marine animal biomass and ecosystem structure across ocean basins. Global Change Biol., 25(2), pp. 459-472. 
Ciutat, A., Widdows, J. \& Pope, N. D., 2007. Effect of Cerastoderma edule density on near-bed hydrodynamics and stability of cohesive muddy sediments. J. Exp. Mar. Bio. Ecol., 346(1-2), pp. 114-126.

Cozzoli, F. et al., 2018. The combined influence of body size and density on cohesive sediment resuspension by bioturbators. Sci. Rep., 12.8(3831).

Cozzoli, F., Bouma, T. J., Ysebaert, T. \& Herman, P. M. J., 2013. Application of non-linear quantile regression to macrozoobenthic species distribution modelling: Comparing two contrasting basins. Mar. Ecol. Prog. Ser., Volume 475, pp. 119-133.

Cozzoli, F. et al., 2014. A mixed modeling approach to predict the effect of environmental modification on species distributions.. PLoS One, Volume 9, p. 15-17.

Cozzoli, F. et al., 2019. A process based model of cohesive sediment resuspension under bioturbators' influence. Sci. Tot. Env., Volume 670, pp. 18-30.

Donadi, S. et al., 2013. Cross-habitat interactions among bivalve species control community structure on intertidal flats. Ecology, Volume 94, pp. 489-498.

Dossena, M. et al., 2012. Warming alters community size structure and ecosystem functioning. Proc. R. Soc. Lond. B. Biol. Sci., 279(1740), pp. 3011-3019.

Fagherazzi, S. \& Wiberg, P. L., 2009. Importance of wind conditions, fetch, and water levels on wave-generated shear stresses in shallow intertidal basins. J. Geophys. Res., Volume 114, p. F03022.

Fang, X. et al., 2019. Spatio-temporal variation in sediment ecosystem processes and roles of key biota in the Scheldt estuary. Estuar. Coast. Mar. Sci., Volume 222, pp. 21-31.

Fernández-Tajes, J. et al., 2011. Use of three bivalve species for biomonitoring a polluted estuarine environment. Environ. Monit. Assess., Volume 177, pp. 289-300.

Flach, E., 1996. The influence of the cockle, Cerastoderma edule, on the macrozoobenthic community of tidal flats in the Wadden Sea. Mar. Ecol. - PSZNI, 17(I), pp. 87-98. 
Friedrichs, C. T., 2011. Tidal Flat Morphodynamics. In: E. Wolanski \& D. McLusky, red. Tidal Flat Morphodynamics. sl:Elsevier, p. 4590.

Friedrichs, M., Leipe, T., Peine, F. \& Graf, G., 2009. Impact of macrozoobenthic structures on near-bed sediment fluxes. J. Mar. Sys., Volume 75, p. 336-347.

Gao, S., 2019. Geomorphology and sedimentology of tidal flats. In: G. Perillo, E. Wolanski, D. Cahoon \& C. Hopkinson, red. Coastal Wetlands. sl:Elsevier Science, pp. 359-381.

Gilbert, F. et al., 2007. Sediment reworking by marine benthic species from the GullmarFjord (Western Sweden): Importance of faunal biovolume. J. Exp. Mar. Biol. Ecol., Volume 348, p. 133-144.

Gjoni, V. \& Basset, A., 2018. A cross-community approach to energy pathways across lagoon macroinvertebrate guilds. Estuaries Coast., 41(8), pp. 2433-2446.

Gjoni, V., Cozzoli, F., Rosati, I. \& Basset, A., 2017. Size-Density Relationships: a CrossCommunity approach to benthic macroinvertebrates in Mediterranean and Black Sea Lagoons. Estuaries Coast., 40(4).

Glazier, D. S., 2005. Beyond the '3/4-power law': variation in the intra- and interspecific scaling of metabolic rate in animals. Biol. Rev., Volume 80, pp. 611-662.

Gogina, M. et al., 2018. In search of a field-based relationship between benthic macrofauna and biogeochemistry in a modern brackish coastal sea. Front. Mar. Sci., 5(489).

Gogina, M. et al., 2020. Interregional comparison of benthic ecosystem functioning: community bioturbation potential in four regions along the NE Atlantic shelf. Ecol. Ind., $110(105945)$.

Grabowski, R. C., Droppo, I. G. \& Wharton, G., 2011. Erodibility of cohesive sediment: The importance of sediment properties. Earth-Sci. Rev., 105(3-4), pp. 101-120.

Harris, J. et al., 2015. Biotic interactions influence sediment erodibility on wave-exposed sandflats. Mar. Ecol. Prog. Ser., Volume 523, pp. 15-30. 
Harris, J. et al., 2015. Biotic interactions influence sediment erodibility on wave-exposed sandflats. Mar. Ecol. Prog. Ser., Volume 523, pp. 15-30.

Harris, L. A., Duarte, C. M. \& Nixon, S. W., 2006. Allometric laws and prediction in estuarine and coastal ecology. Estuaries Coast., 29(2).

Hayter, E. J. \& Mehta, A. J., 1986. Modelling cohesive sediment transport in estuarial waters. Appl. Math. Model., Volume 10, pp. 294-303.

Hillman, J. R., Lundquist, C. J., Pilditch, C. A. \& Thrush, S. F., 2019. The role of large macrofauna in mediating sediment erodibility across sedimentary habitats. Limnol. Oceanogr., Volume doi:10.1002/lno.11337.

Hou, C. et al., 2008. Energy uptake and allocation during ontogeny. Science, 322(5902), pp. 736-739.

Humphries, M. M. \& McCann, K. S., 2014. Metabolic ecology. J. Anim. Ecol., 83(1), pp. 7-19. Jørgensen, L. L. et al., 2019. Impact of multiple stressors on sea bed fauna in a warming Arctic. Mar. Ecol. Prog. Ser., Volume 608, pp. 1-12.

Joensuu, M. et al., 2018. Sediment properties, biota, and local habitat structure explain variation in the erodibility of coastal sediments. Limnol. Oceanogr., Volume 63, p. 173-186.

Jones, C. G., Lawton, J. H. \& Shachak, M., 1994. Organisms as ecosystem engineers. Oikos, Volume 69, pp. 373-386.

Jones, C. G., Lawton, J. H. \& Shachak, M., 1997. Positive and negative effects of organisms as physical ecosystem engineers. Ecology, Volume 78, pp. 1946-1957.

Kater, B., Geurts van Kessel, A. \& Baars, J., 2006. Distribution of cockles cerastoderma edule in the eastern scheldt: habitat mapping with abiotic variables. Mar. Ecol. Prog. Ser., Volume 318, pp. 221-227.

Kooijman, S. A. L. M., 2000. Dynamic energy and mass budgets in biological systems. Cambridge: Cambridge University Press. 
Kristensen, E. et al., 2013. Influence of benthic macroinvertebrates on the erodability of estuarine cohesive sediments: Density- and biomass-specific responses. Estuar. Coast. Shelf Sci., Volume 134, pp. 80-87.

Kristensen, E. et al., 2012. What is bioturbation? The need for a precise definition for fauna in aquatic sciences. Mar. Ecol. Prog. Ser., Volume 446, pp. 285-302.

Kuznetsova, A., Brockhoff, P. B. \& Christensen, R. H. B., 2017. lmerTest Package: Tests in Linear Mixed Effects Models. J. Stat. Soft., 82(13), pp. 1-26.

Le Hir, P., Monbet, Y. \& Orvain, F., 2007. Sediment erodability in sediment transport modelling: Can we account for biota effects?. Conti. Shelf Res., Volume 27, pp. 11161142

Le Hir, P. et al., 2000. Characterization of intertidal flat hydrodynamics. Cont. Shelf Res., 20(12-13), pp. 1433-1459.

Li, B. et al., 2019. Effects of key species mud snail Bullacta exarata (Gastropoda) on oxygen and nutrient fluxes at the sediment-water interface in the Huanghe River Delta, China. Acta Oceanol. Sin., 38(8), pp. 48-55.

Li, B. et al., 2017. Bioturbation effect on the erodibility of cohesive versus non-cohesive sediments along a current velocity gradient: a case study on cockles. J. Exp. Mar. Biol. Ecol., Volume 496, pp. 84-90.

Lin, D. et al., 2018. Bioturbation facilitates DDT sequestration by activated carbon against recontamination by sediment deposition. Environ. Toxicol. Chem., 37(7), pp. 20132021.

Lindmark, M., Ohlberger, J., Huss, M. \& Gårdmark, A., 2018. Size-based ecological interactions drive food web responses to climate warming. bioRxiv, Volume 430082. 
Lukwambe, B. et al., 2018. Bioturbation by the razor clam(Sinonovacula constricta) on the microbial community and enzymatic activities in the sediment of an ecological aquaculture wastewater treatment system. Sci. Tot. Env., Volume 643, pp. 1098-1107.

Maire, O. et al., 2006. Effects of food availability on sediment reworking in Abra ovata and A. nitida. Mar. Ecol. Prog. Ser., Volume 319, pp. 135-153.

Martin, B. T. et al., 2013. Predicting population dynamics from the properties of individuals: A cross-level test of dynamic energy budget theory. Am. Nat., 181(4), pp. 506-519.

Mehta, A. \& Partheniades, E., 1982. Resuspension of deposited cohesive sediment beds. Cape Town, 18th Conference on Coastal Engineering ASCE.

Mermillod-Blondin, F. et al., 2018. Influence of tubificid worms on sediment structure, benthic biofilm and fauna in wetlands: A field enclosure experiment. Freshwater Biol., 63(11), pp. $1420-1432$.

Meysman, F. J., Middelburg, J. J. \& Heip, C. H., 2006. Bioturbation: a fresh look at Darwin's last idea. Trend. Ecol. Evol., 21(12), pp. 688-695.

Montserrat, F. et al., 2008. Benthic community-mediated sediment dynamics. Mar. Ecol. Prog. Ser., Volume 372, pp. 43-59.

Montserrat, F. et al., 2009. Sediment segregation by biodiffusing bivalves. Estuar. Coast. Mar. Sci., 83(4), pp. 379-391.

Moore, J. W., 2006. Animal ecosystem engineers in streams. BioScience, Volume 56, pp. 237246.

Nasermoaddeli, M. H. et al., 2018. A model study on the large-scale effect of macrofauna on the suspended sediment concentration in a shallow shelf sea. Estuar. Coast. Mar. Sci., Volume 211, pp. 62-76.

Neumeier, U., Lucas, C. H. \& Collins, M., 2006. Erodibility and erosion patterns of mudflat sediments investigated using an annular flume. Aquat. Ecol., Volume 40, pp. 543-554. 
Nguyen, H. M., Bryan, K. R., Pilditch, C. A. \& Moon, V. G., 2019. Influence of ambient temperature on erosion properties of exposed cohesive sediment from an intertidal mudflat.. Geo Marine Lett., 39(4), pp. 337-347.

Nilsson, H. C. \& Rosenberg, R., 2002. Succession in marine benthic habitats and fauna in response to oxygen deficiency: analysed by sediment profile-imaging and by grab samples. Mar. Ecol. Prog. Ser., Volume 197, pp. 139-149.

Ong, E. Z., Briff, M., Moens, T. \& Van Colen, C., 2017. Physiological responses to ocean acidification and warming synergistically reduce condition of the common cockle Cerastoderma edule. Mar. Env. Res., Volume 130, pp. 38-47.

Orvain, F., 2005. A model of sediment transport under the influence of surface bioturbation: generalisation to the facultative suspension-feeder Scrobicularia plana. Mar. Ecol. Prog. Ser., Volume 286, pp. 43-56.

Orvain, F., Le Hir, P. \& Sauriau, P. G., 2003. A model of fluff layer erosion and subsequent bed erosion in the presence of the bioturbator, Hydrobia ulvae. J. Mar. Res., Volume 61, pp. 823-851.

Orvain, F., Le Hir, P., Sauriau, P. G. \& S., L., 2012. Modelling the effects of macrofauna on sediment transport and bed elevation: Application over a cross-shore mudflat profile and model validation. Estuar. Coast. Mar. Sci., Volume 108, pp. 64-75.

Orvain, F., Sauriau, P. G., Bacher, C. \& Prineau, M., 2006. The influence of sediment cohesiveness on bioturbation effects due to Hydrobia ulvae on the initial erosion of intertidal sediments: a study combining flume and model approaches. J. Sea Res. , 55(1), pp. 54-73.

Orvain, F. et al., 2007. Spatio-temporal variations in intertidal mudflat erodability: MarennesOléron Bay, western France. Cont. Shelf Res., 27(8), pp. 1153-1173. 
Pearson, T. H. \& Rosenberg, R., 1978. Macrobenthic succession in relation to organic enrichment and pollution of the marine environment. Oceanogr. Mar. Biol. Ann. Rev., Volume 5, pp. 229-311.

Porter, E. T., Owens, M. S. \& Cornwell, J. C., 2006. Effect of sediment manipulation on the biogeochemistry of experimental sediment systems. J. Coast. Res., 22(6), pp. 15391551.

Queirós, A. M. et al., 2013. A bioturbation classification of E uropean marine infaunal invertebrates. Ecol. Evol., 3(11), pp. 3958-3985.

R Core Team, 2019. R: A language and environment for statistical computing. [Online] Available at: https://www.R-project.org/

Rakotomalala, C. et al., 2015. Modelling the effect of Cerastoderma edule bioturbation on microphytobenthos resuspension towards the planktonic food web of estuarine ecosystem. Ecol. Model., Volume 316, pp. 155-167.

Roberts, W., Le Hir, P. \& Whitehouse, R., 2000. Investigation using simple mathematical models of the effect of tidal currents and waves on the profile shape of intertidal mudflats. Cont. Shelf Res., 20(10-11), pp. 1079-1097.

Rosenfeld, J., Van Leeuwen, T., Richards, J. \& Allen, D., 2015. Relationship between growth and standard metabolic rate: measurement artefacts and implications for habitat use and life-history adaptation in salmonids. J. Anim. Ecol., 84(1), pp. 4-20.

Salvador de Paiva, J. N., Walles, B., Ysebaert, T. \& Bouma, T. J., 2018. Understanding the conditionality of ecosystem services: The effect of tidal flat morphology and oyster reef characteristics on sediment stabilization by oyster reefs. Ecol. Eng., Volume 112, pp. $89-95$. 
Sandford, L. P., 2008. Modeling a dynamically varying mixed sediment bed with erosion, deposition, bioturbation, consolidation, and armoring. Comput. Geosci., Volume 34, pp. $1263-1283$.

Savelli, R. et al., 2019. Impact of chronic and massive resuspension mechanisms on the microphytobenthos dynamics in a temperate intertidal mudflat. J. Geophys. Res. Biogeo., Volume 124.

Shimeta, J., Amos, C. L., Beaulieu, S. E. \& Ashiru, O. M., 2002. Sequential resuspension of protists by accelerating tidal flow: implications for community structure in the benthic boundary layer. Limnol. Oceanogr., 47(4), pp. 1152-1164.

Shokri, M. et al., 2019. Components of standard metabolic rate variability in three species of gammarids. Web Ecology, 19(1), pp. 1-13.

Silva, R. et al., 2019. The incorporation of biophysical and social components in coastal management. Estuaries Coast., pp. 1-14.

Smaal, A. C., Vonck, A. P. M. A. \& Bakker, M., 1997. Seasonal variation in physiological energetics of Mytilus edulis and Cerastoderma edule of different size classes. J. Mar. Biol. Assoc. U. K., 77(3), pp. 817-838.

Soissons, L. M. et al., 2019. Sandification vs. muddification of tidal flats by benthic ecosystem engineers: a flume study. Estuar. Coast. Mar. Sci., Volume 228, p. 106355.

Solan, M. et al., 2004b. In situ quantification of bioturbation using time lapse fluorescent sediment profile imaging (f SPI), luminophore tracers and model simulation. Mar. Ecol. Prog. Ser., Volume 271, pp. 1-12.

Sutherland, T. \& Grant, J., 1998. The effect of carbohydrate production by the diatom Nitzschia curvilineata on the erodibility of sediment. Limnol. Ocenogr., 41(1), pp. 65-72. 
Ubertini, M. L. S., Gangnery, A., Grangere,'. K. \& LeGendre, R. O. F., 2012. Spatial variability of benthic-pelagic coupling in an estuary ecosystem: Consequences for microphytobenthos resuspension phenomenon. Plos One, Volume 7.

Van der Biest, K. et al., 2020. Aligning biodiversity conservation and ecosystem services in spatial planning: Focus on ecosystem processes. Sci. Tot. Env., Volume 712, p. 136350. van der Meer, J., 2006. An introduction to Dynamic Energy Budget (DEB) models with special emphasis on parameter estimation. J. Sea Res., 56(2), pp. 85-102.

van Ledden, M., van Kesteren, V. M. G. \& Winterwerp, J. C., 2004. A conceptual framework for the erosion behaviour of sand-mud mixtures. Cont. Shelf Res., Volume 24, pp. 1-11. van Prooijen, B. C., Montserrat, F. \& Herman, P. M. J., 2011. A process-based model for erosion of Macoma balthica-affected mud beds. Cont. Shelf Res., Volume 31, p. 527538.

van Prooijen, B. C. \& Winterwerp, J., 2010. A stochastic formulation for erosion of cohesive sediments. J. Geophys. Res., 115(C01005).

van Rijn, L. C., 2007. Unified view of sediment transport by currents and waves. I: Initiation of motion, bed roughness, and bed-load transport. J. Hydraul. Eng., Volume 133, pp. 649-667.

Verdelhos, T., Marques, J. \& Anastácio, P., 2015a. Behavioral and mortality responses of the bivalves Scrobicularia plana and Cerastoderma edule to temperature, as indicator of climate change's potential impacts. Ecol. Ind., Volume 58, pp. 95-103.

Verdelhos, T., Marques, J. \& Anastácio, P., 2015b. The impact of estuarine salinity changes on the bivalves Scrobicularia plana and Cerastoderma edule, illustrated by behavioral and mortality responses on a laboratory assay. Ecol. Ind., Volume 52, pp. 96-104.

Vladimirova, I., Kleimenov, S. \& Radzinskaya, L., 2003. The relation of energy metabolism and body weight in bivalves (Mollusca: Bivalvia). Biology Bull., 30(4), pp. 392-399. 
Volkenborn, N., Robertson, D. \& Reise, K., 2009. Sediment destabilizing and stabilizing bioengineers on tidal flats: Cascading effects of experimental exclusion. Helgol. Mar. Res., Volume 63, pp. 27-35.

Walles, B. et al., 2015. The ecosystem engineer Crassostrea gigas affects tidal flat morphology beyond the boundary of their reef structures. Estuaries Coast., Volume 38, pp. 941-959.

West, G., Brown, J. H. \& Enquist, B., 1997. A general model for the origin of allometric scaling laws in biology. Science, Volume 276, p. 122-126.

Widdows, J. \& Brinsley, M., 2002. Impact of biotic and abiotic processes on sediment dynamics and the consequences to the structure and functioning of the intertidal zone.. J. Sea Res., 48(2), pp. 143-156.

Widdows, J., Brinsley, M., Salkeld, P. \& Elliott, M., 1998. Use of annular flumes to determine the influence of current velocity and bivalves on material flux at the sediment-water interface. Estuaries, Volume 21, pp. 552-559.

Widdows, J. \& Navarro, J. M., 2007. Influence of current speed on clearance rate, algal cell depletion in the water column and resuspension of biodeposits of cockles (Cerastoderma edule). J. Exp. Mar. Biol. Ecol., 343(1), pp. 44-51.

Wilkes, M. A. et al., 2019. Physical and biological controls on fine sediment transport and storage in rivers. WIRES Water, 6(2), p. e1331.

Willows, R., Widdows, J. \& Wood, R., 1998. Influence of an infaunal bivalve on the erosion of an intertidal cohesive sediment: A flume and modeling study. Limnol. Oceanogr., Volume 43, pp. 1332-1343.

Winterwerp, J. C. \& van Kesteren, W., 2004. Introduction to the physics of cohesive sediment in the marine environment. Amsterdam: Elsevier.

Winterwerp, J. C. et al., 2018. Efficient consolidation model for morphodynamic simulations in Low-SPM environments. J. Hydraul. Eng., 144(8), p. 04018055. 
Wood, R. \& Widdows, J., 2002. A model of sediment transport over an intertidal transect, comparing the influences of biological and physical factors. Limnol. Oceanogr., 47(3), pp. $848-855$.

Wrede, A. et al., 2019. Macrofaunal irrigation traits enhance predictability of nutrient fluxes across the sediment-water interface. Mar. Ecol. Prog. Ser., Volume 632, pp. 27-42.

Wrede, A. et al., 2018. Organism functional traits and ecosystem supporting services-A novel approach to predict bioirrigation. Ecol. Ind., Volume 91, pp. 737-743.

Xie, M., Simpson, S. L. \& Wang, W. X., 2019. Bioturbation effects on metal release from contaminated sediments are metal-dependent. Environ. Pollut., Volume 250, pp. 87-96.

Yvon-Durocher, G. et al., 2012. Reconciling the temperature dependence of respiration across timescales and ecosystem types. Nature, Volume 487, pp. 472-473.

Zhou, Z. et al., 2015. Modeling sorting dynamics of cohesive and non-cohesive sediments on intertidal flats under the effect of tides and wind waves. Cont. Shelf. Res., Volume 104, pp. 76-91.

Zhu, Z. et al., 2016. Interactive effects between physical forces and ecosystem engineers on seed burial: a case study using Spartina anglica. Oikos, 125(1), pp. 98-106.

Zwarts, L., Blomert, A., Spaak, P. \& de Vries, B., 1994. Feeding radius, burying depth and siphon size of Macoma balthica and Scrobicularia plana. J. Exp. Mar. Biol. Ecol., 183(2), pp. 193-212. 


\section{TABLES}

Table 1: Types of sediment composition. Percentages in volume of the different sediment size classes ( silt $<63 \mu \mathrm{m}$; very fine sand $63-125 \mu \mathrm{m}$; fine sand $125-250 \mu \mathrm{m}$; medium sand 250-500 $\mu \mathrm{m}$; coarse sand $>500 \mu \mathrm{m}$ ) and median (D50), tenth (D10) and ninetieth percentile (D90) of the sediment grain size distribution $(\mu \mathrm{m})$.

\begin{tabular}{rrrrrrrr}
\hline \hline Silt & Very fine & Fine & Medium & Coarse & D10 & D50 & D90 \\
$(\%)$ & $(\%)$ & $(\%)$ & $(\%)$ & $(\%)$ & $(\mu \mathrm{m})$ & $(\mu \mathrm{m})$ & $(\mu \mathrm{m})$ \\
\hline 0 & 0 & 30 & 61 & 9 & 189 & 305 & 488 \\
4 & 1 & 31 & 55 & 9 & 159 & 291 & 489 \\
10 & 5 & 33 & 45 & 7 & 94 & 257 & 468 \\
28 & 14 & 30 & 24 & 3 & 8 & 153 & 383
\end{tabular}


Table 2: Bioturbators size classes. Sediment resuspension was measured in the abiotic controls and in 4 treatments with biomass equivalents (overall biomass $19 \mathrm{~g}$ Ash Free Dry Weight $\mathrm{m}^{-2}$ ) of differently sized bioturbators ( $M, \mathrm{mg}$ AFDW).

\begin{tabular}{rrr}
\hline \hline Shell length & Body mass & Density of individuals \\
$(\mathrm{mm})$ & $(M, \mathrm{mg}$ AFDW $)$ & $\left(D\right.$, Ind. $\left.\mathrm{m}^{-2}\right)$ \\
15 & 36 & 530 \\
20 & 93 & 247 \\
27 & 247 & 77 \\
35 & 576 & 33
\end{tabular}


Table 3: For each treatment with different sediment silt volume content (\%) and bioturbators individual body mass $\left(M, \mathrm{mg}\right.$ AFDW), the critical flow velocity for erosion $\left(\mathrm{cm} \mathrm{sec}^{-1}\right)$ were estimated as the zero $R_{T O T}$ intercept from a regression of measured $R_{T O T}$ against $V$ (Kristensen, et al., 2013).

\begin{tabular}{rrrrr}
\hline \hline & & \multicolumn{1}{l}{$\boldsymbol{V}$ - } & \multicolumn{3}{c}{ Critical flow velocity } \\
Silt (\%) & \multicolumn{1}{c}{$\boldsymbol{M}$} & Intercept & V-Slope & for erosion \\
\hline 0 & 0 & -121.3 & 7.8 & 15.5 \\
0 & 36 & -48.6 & 5.7 & 8.5 \\
0 & 93 & -75.2 & 5.1 & 14.8 \\
0 & 247 & -53.6 & 6.2 & 8.58 \\
0 & 576 & -88.8 & 6.2 & 14.4 \\
4 & 0 & -167.8 & 11.1 & 15.2 \\
4 & 36 & -92.2 & 16.2 & 5.7 \\
4 & 93 & -70.1 & 14 & 5 \\
4 & 247 & -77.6 & 14.5 & 5.4 \\
4 & 576 & -106 & 11 & 9.6 \\
10 & 0 & -100.1 & 5.8 & 17.2 \\
10 & 36 & -108.5 & 9.6 & 11.3 \\
10 & 93 & -102.6 & 9.5 & 10.8 \\
10 & 576 & -102.2 & 8.1 & 12.6 \\
28 & 0 & -94.3 & 6.9 & 13.6 \\
28 & 36 & -103.1 & 9.3 & 11.1 \\
28 & 93 & -91.7 & 7.9 & 11.6 \\
28 & 247 & -76.3 & 6.4 & 12 \\
28 & 576 & -98.1 & 7.6 & 13
\end{tabular}


Table 4: Number of observations included in the ANCOVA model of the amount of suspended sediment due to bioturbation $\left(R_{B I O}, \mathrm{~g} \mathrm{~m}^{-2}\right.$, Table 5$)$. The initial number of $192 R_{B I O}$ measures (4 silt levels X 4 size levels X 6 current velocity step X 2 replicates) was reduced to 135 in way to avoid observations biased by optical disturbance to the sensor, observations related to mass erosion events and observations of decreased sediment resuspension in presence of bioturbators.

\begin{tabular}{r|cccc} 
& \multicolumn{4}{|c}{ Body mass (mg AFDW) } \\
Silt (\%) & 36 & 93 & 247 & 576 \\
\hline 0 & $9^{\mathrm{b}, \mathrm{c}}$ & $9^{\mathrm{b}}$ & $10^{\mathrm{b}}$ & $7^{\mathrm{b}}$ \\
\hline 10 & $8^{\mathrm{d}}$ & $6^{\mathrm{c}, \mathrm{d}}$ & $8^{\mathrm{d}}$ & $8^{\mathrm{d}}$ \\
\hline 28 & $6^{\mathrm{d}}$ & $12^{\mathrm{a}}$ & $0^{\mathrm{e}}$ & $12^{\mathrm{a}}$ \\
& $6^{\mathrm{d}}$ & $12^{\mathrm{a}}$ & $12^{\mathrm{a}}$ & $11^{\mathrm{c}}$
\end{tabular}

a: complete set of 12 measures for treatment (6 current velocity steps $X 2$ replicates)

b: observations missing due reduction in sediment resuspension with bioturbators

c: observations missing due to optical disturbance to the OBS sensor

$d$ : observations missing due to mass erosion events

e: observations missing due to mass erosion events (whole treatment) 
Table 5: Summary of the mixed ANCOVA model of the amount of suspended sediment due to bioturbation $\left(R_{B I O}, \mathrm{~g} \mathrm{~m}^{-2}\right)$ using the silt content of the sediment as categorical explanatory variable and the current velocity $\left(V, \mathrm{~cm} \mathrm{sec}^{-1}\right)$ and the individual mass of the bioturbators $(M$, mg AFDW) as continuous explanatory variables. The response variable $R_{B I O}$ and the explanatory variable $M$ were normalized via log transformation. A third degree polynomial function of the variable $V$ was used to account for non-linearity in the relationship between current velocity and $R_{B I O}$. Since we took repeated measurements of the same experimental units through a $V$ gradient, we included the experimental runs as random term in the ANCOVA to account for non-independence of the observations. Selection of predictive variables and interaction terms was assessed by a bi-directional elimination stepwise procedure. Only significant variables and interaction terms are reported in the summary table. The full model (i.e. prior to variables selection) is available as an appendix (Appendix C).

\begin{tabular}{|c|c|c|c|}
\hline & & $\log \left(R_{B I O}\right)$ & \\
\hline Predictors & Estimates & $95 \% C I$ & $p$ \\
\hline (Intercept) & 1.47 & $0.23-2.72$ & 0.028 \\
\hline $\log (M)$ & -0.42 & $-0.64--0.20$ & 0.001 \\
\hline$V$ & 0.24 & $0.20-0.28$ & $<0.001$ \\
\hline$V^{3}$ & -0.0002 & $-0.0002--0.0001$ & $<0.001$ \\
\hline Silt $4 \%$ & 1.01 & $0.34-1.69$ & 0.006 \\
\hline Silt $10 \%$ & 0.46 & $-0.27-1.19$ & 0.228 \\
\hline Silt $28 \%$ & 0.13 & $-0.54-0.80$ & 0.702 \\
\hline$V^{3}:$ Silt $4 \%$ & 0.0003 & $0.0002-0.0003$ & $<0.001$ \\
\hline$V^{3}:$ Silt $10 \%$ & 0.0001 & $0.0001-0.0002$ & $<0.001$ \\
\hline$V^{3}:$ Silt $28 \%$ & 0.0001 & $0.0001-0.0002$ & $<0.001$ \\
\hline \multicolumn{4}{|l|}{ Random Effects } \\
\hline$\sigma^{2}$ & 0.37 & & \\
\hline$\tau_{00 \text { Run }}$ & 0.29 & & \\
\hline ICC & 0.44 & & \\
\hline $\mathrm{N}_{\text {Run }}$ & 28 & & \\
\hline Observations & 135 & & \\
\hline Marginal $\mathrm{R}^{2}$ / Conditional $\mathrm{R}^{2}$ & $0.77 / 0.87$ & & \\
\hline
\end{tabular}




\section{FIGURE}

Biological drivers

Fixed biomass

(19 $\left.\mathrm{g} \mathrm{AFDW} \mathrm{m}^{-2}\right)$
Physical drivers

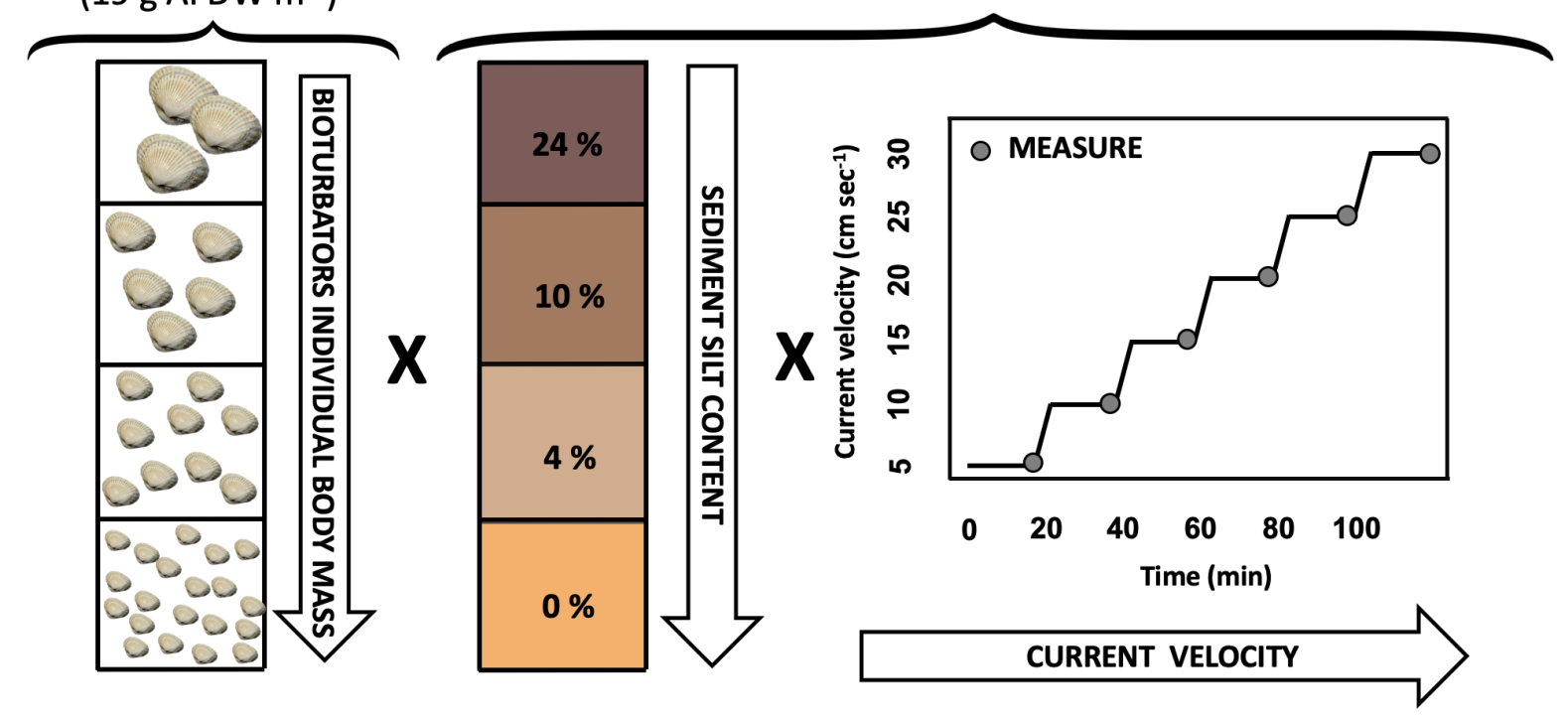

Figure 1: Experimental design. Keeping fixed an overall C. edule biomass of $19 \mathrm{~g}$ AFDW m ${ }^{2}$, we crossed in a full factorial design 4 different size classes of individuals (36, 93, 247 and $576 \mathrm{mg}$ AFDW of individual body mass $), 4$ levels of sediment silt volume content $(0 \%, 4 \%$, $10 \%$ and $28 \%$ ) and 6 levels of current velocity (from 5 to $30 \mathrm{~cm} \mathrm{sec}^{-1}$ by steps of $5 \mathrm{~cm} \mathrm{sec}^{-1}$, each step lasting 20 minutes). Each of the experimental runs with bioturbators was associated to a control run using the same sediment type and current velocity gradient but without bioturbators. Each experimental treatment was replicated twice. 

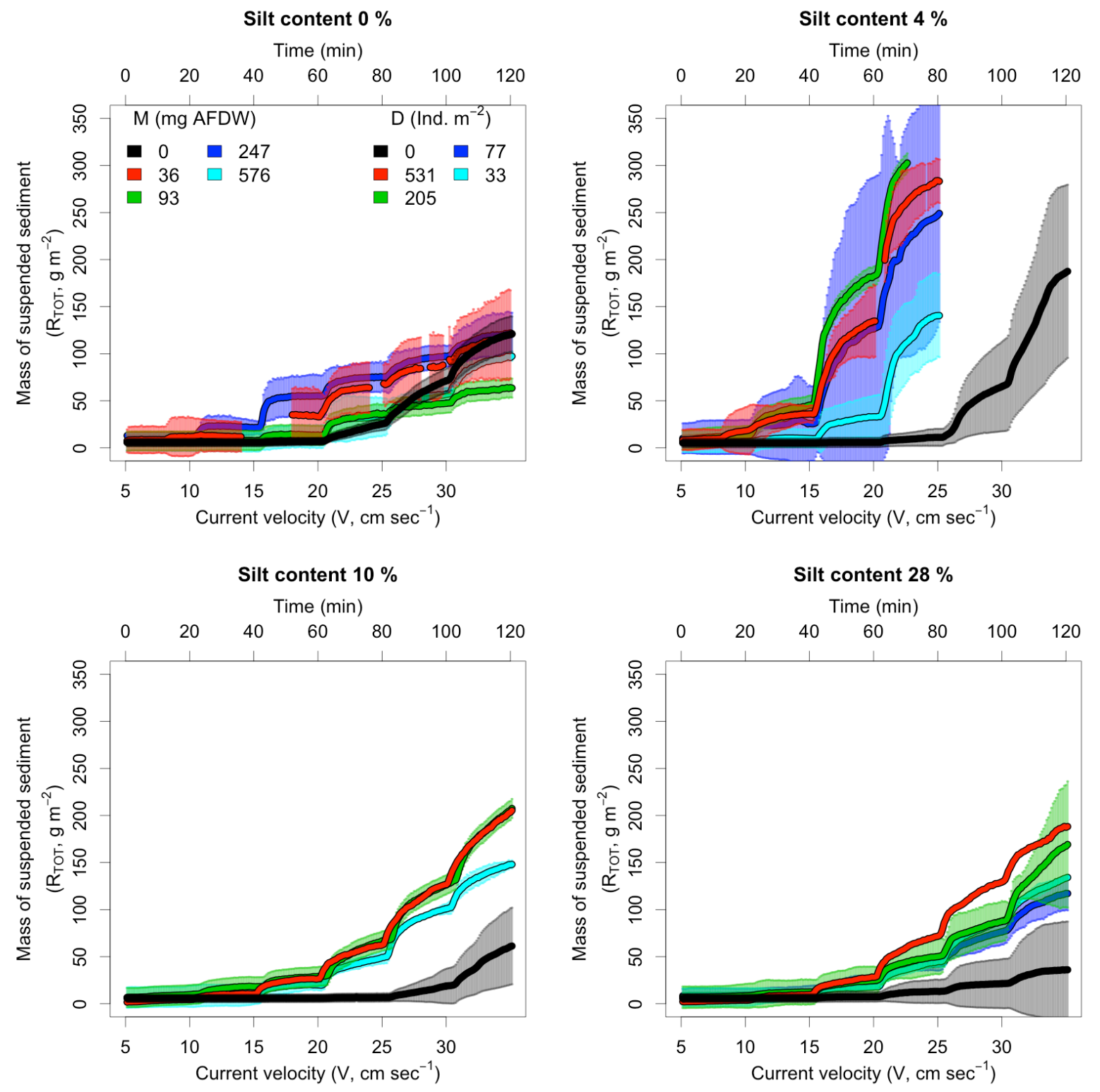

Figure 2: Overall mass of suspended sediment $\left(R_{T O T}, \mathrm{~g} \mathrm{~m}^{-2}\right)$ for different sediment silt volume content $(\%)$ across a gradient of current velocity $\left(V, \mathrm{~cm} \mathrm{sec}^{-1}\right)$ and bioturbators individual body mass ( $M, \mathrm{mg}$ AFDW, coloured lines), average of two replicates for each treatment (when available). The coloured areas represent the $95 \%$ confidence intervals around the average trends. 
Silt content $0 \%$

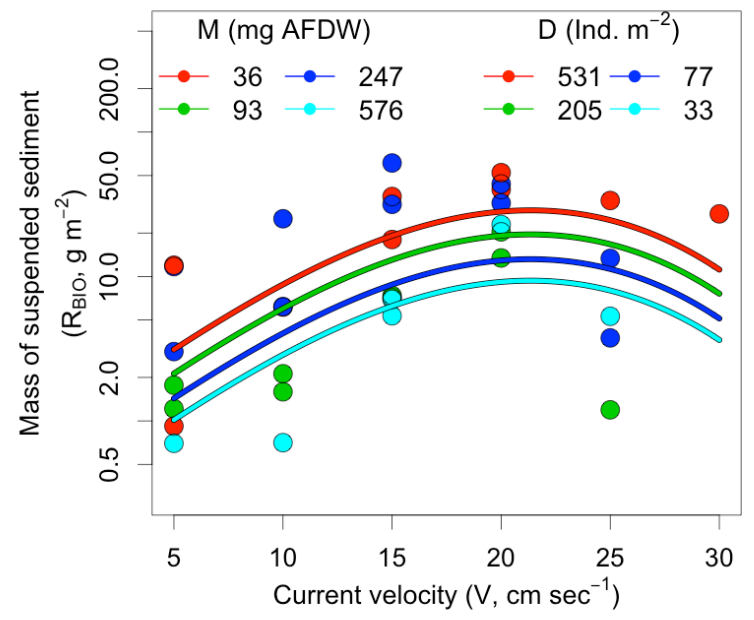

Silt content $10 \%$

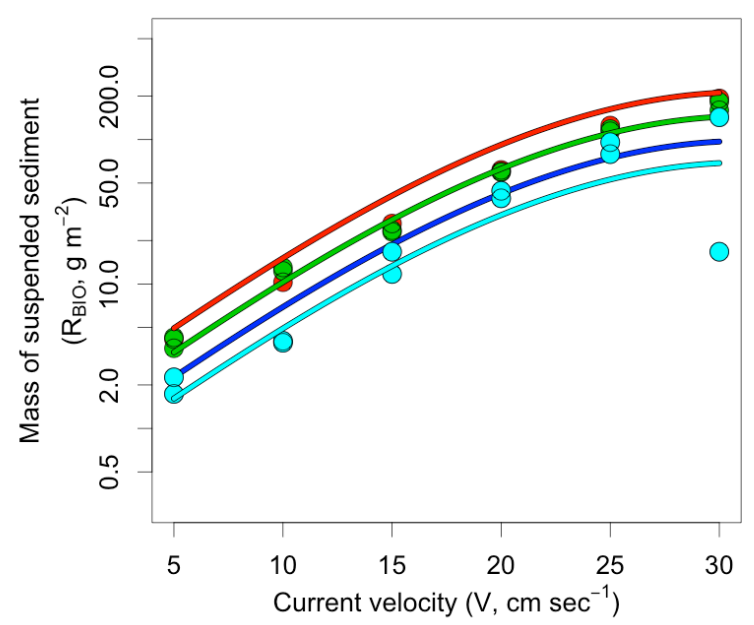

Silt content $4 \%$

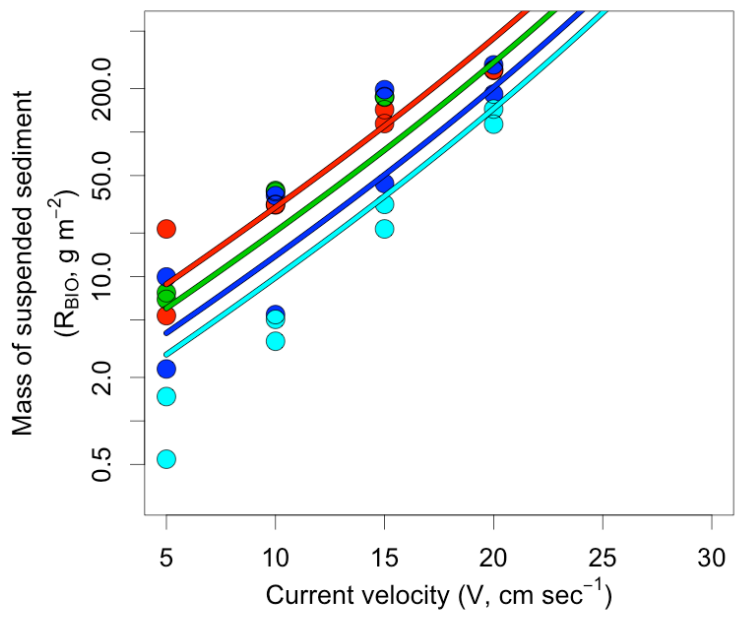

Silt content $28 \%$

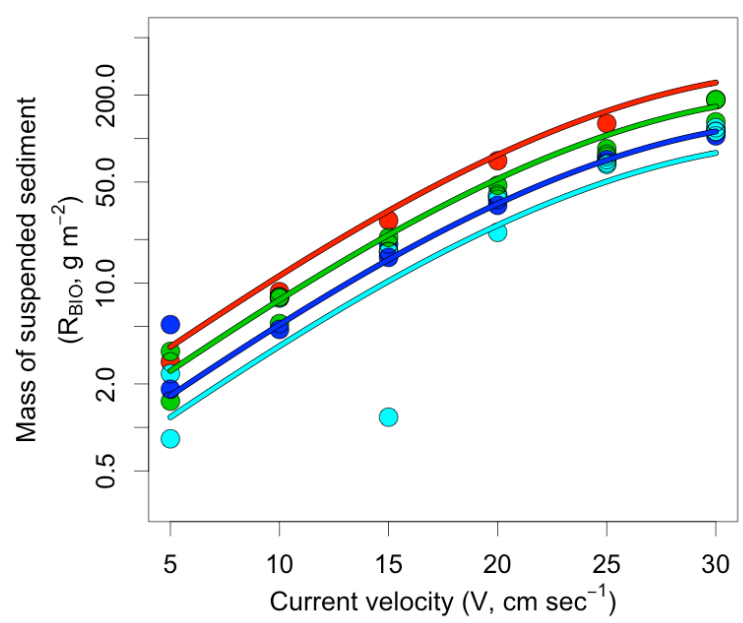

Figure 3: Relationship between current velocity $\left(V, \mathrm{~cm} \mathrm{sec}^{-1}\right)$ and mass of suspended sediment due to bioturbation $\left(R_{B I O}, \mathrm{~g} \mathrm{~m}^{-2}\right)$ for different sediment silt volume content $(\%)$ and bioturbators individual body mass ( $M, \mathrm{mg}$ AFDW), as predicted from the ANCOVA model in Table 5. 
Silt content $0 \%$

Density of individuals (D, Ind. $\mathrm{m}^{-2}$ )

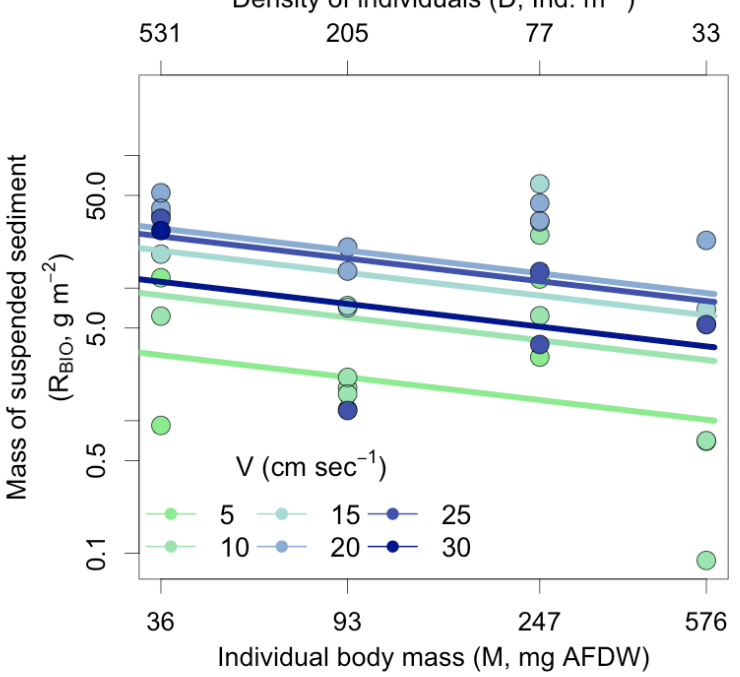

Silt content $10 \%$

Density of individuals (D, Ind. $\mathrm{m}^{-2}$

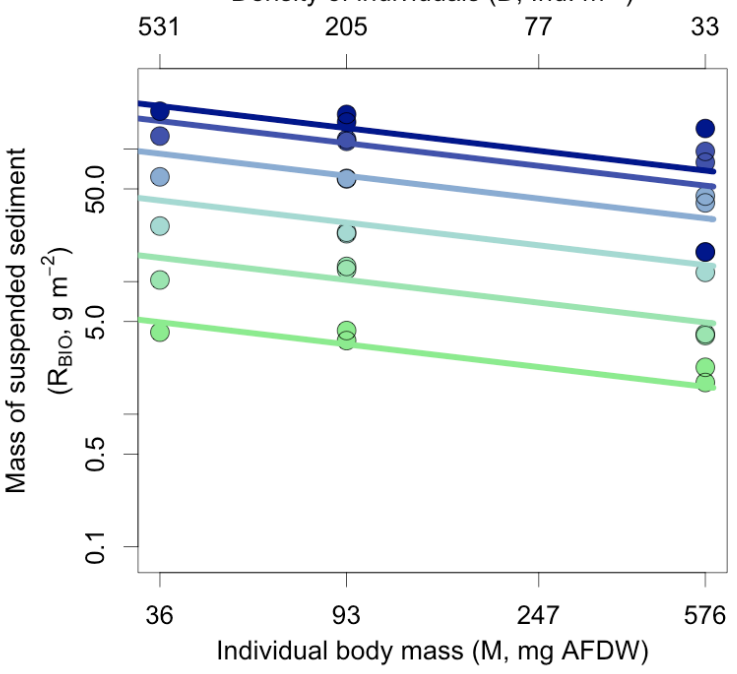

Silt content $4 \%$

Density of individuals ( $D$, Ind. $\mathrm{m}^{-2}$ )

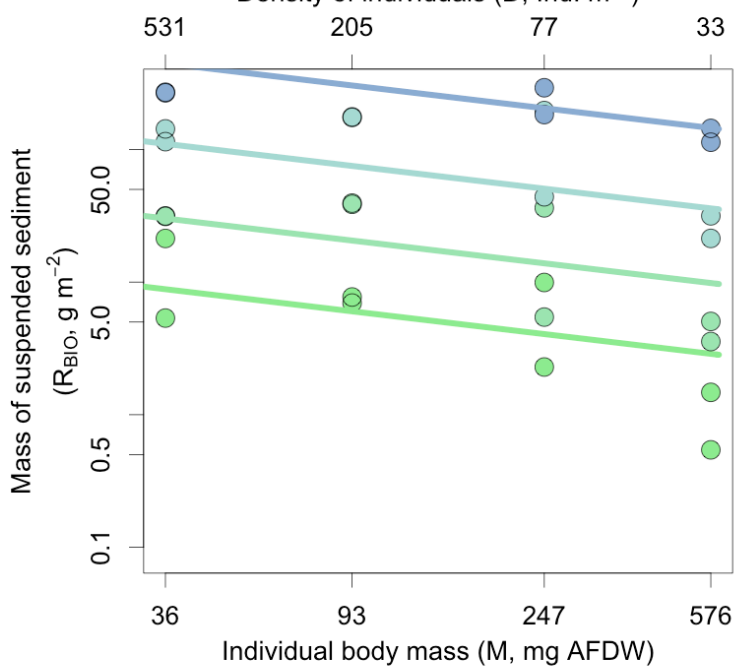

Silt content $28 \%$

Density of individuals (D, Ind. $\mathrm{m}^{-2}$

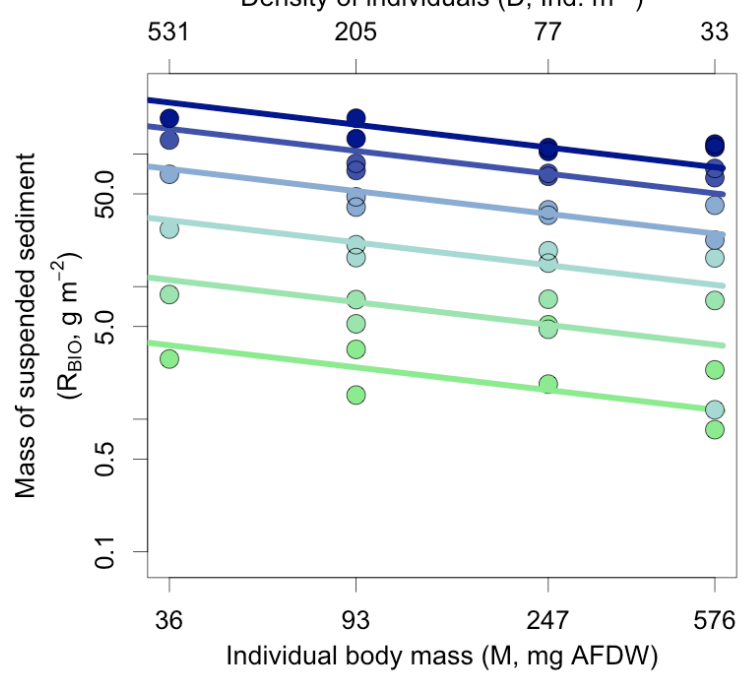

Figure 4: Individual body mass ( $M, \mathrm{mg}$ AFDW) scaling of the mass of suspended sediment due to bioturbation $\left(R_{B I O} \mathrm{~g} \mathrm{~m}^{-2}\right)$ for different sediment silt volume content (\%) and current velocities $\left(V, \mathrm{~cm} \mathrm{sec}^{-1}\right)$, as predicted from the ANCOVA model in Table 5 . 